\title{
Vti1b promotes TRPV1 sensitization during inflammatory pain
}

Julia R Sondermann ${ }^{1}$, Allison M Barry ${ }^{1,2}$, Olaf Jahn ${ }^{3}$, Niklas Michel ${ }^{1}$, Reham Abdelaziz ${ }^{1,4}$, Sebastian Kügler ${ }^{5}$, David Gomez-Varela ${ }^{1}$ and Manuela Schmidt ${ }^{1, *}$

\section{Affiliations}

${ }^{1}$ Somatosensory Signaling and Systems Biology Group; Max-Planck Institute of Experimental Medicine; 37075 Goettingen, Germany

${ }^{2}$ current address: Nuffield Department of Clinical Neurosciences; University of Oxford; OX1 3PT Oxford, UK

${ }^{3}$ Proteomics Group; Max-Planck Institute of Experimental Medicine; 37075 Goettingen, Germany

${ }^{4}$ current address: Oncophysiology Group; Max-Planck Institute of Experimental Medicine; 37075 Goettingen, Germany

${ }^{5}$ Department of Neurology; University Medical Center Goettingen; 37073 Goettingen, Germany

* Correspondence should be addressed to: Manuela Schmidt; Max-Planck Institute of Experimental Medicine. Somatosensory Signaling and Systems Biology Group. 37075, Goettingen, Germany; Tel: +49-551-3899-572; Fax: +49-551-3899-573; E-mail: mschmidt@em.mpg.de

Summary: Discovery of Vti1 b as a novel modulator of TRPV1 during inflammatory pain. Application of functional proteomics to define novel and pain state-dependent binding partners of native TRPV1 in dorsal root ganglia.

Number of text pages: 48 (41 without pages containing figures) Number of figures: 7 Number of Supplemental Digital Content: 9 


\section{Abstract}

Sensitization of the Transient receptor potential ion channel vanilloid 1 (TRPV1) is critically involved in inflammatory pain. To date, manifold signaling cascades have been shown to converge onto TRPV1 and enhance its sensitization. However, many of them also play a role for nociceptive pain which limits their utility as targets for therapeutic intervention. Here, we show that the Vesicle transport through interaction with t-SNAREs homolog 1B (Vti1b) protein promotes TRPV1 sensitization upon inflammation in cell culture, but leaves normal functioning of TRPV1 intact. Importantly, the effect of Vti1b can be recapitulated in vivo: Virus-mediated knockdown of $\mathrm{Vti} 1 \mathrm{~b}$ in sensory neurons attenuated thermal hypersensitivity during inflammatory pain without affecting mechanical hypersensitivity or capsaicin-induced nociceptive pain. Interestingly, TRPV1 and Vti1b are localized in close vicinity as indicated by proximity ligation assays and are likely to bind to each other, either directly or indirectly, as suggested by co-immunoprecipitations. Moreover, using a mass spectrometry-based quantitative interactomics approach, we show that Vti1b is less abundant in TRPV1 protein complexes during inflammatory conditions compared to controls. Alongside, we identify numerous novel and pain state-dependent binding partners of native TRPV1 in dorsal root ganglia. These data represent a unique resource on the dynamics of the TRPV1 interactome and facilitate mechanistic insights into TRPV1 regulation. We propose that inflammationrelated differences in the TRPV1 interactome identified here could be exploited to specifically target inflammatory pain in the future.

\section{Introduction}

TRPV1 is highly enriched in dorsal root ganglia (DRG) and its involvement in diverse pain states has been well documented (for review see [48]). The physiological function of TRPV1 encompasses the detection of noxious thermal $\left(\sim 43^{\circ} \mathrm{C}\right)$ and irritant chemical stimuli to elicit nociceptive pain $[15,48,108]$. The latter crucially prevents bodily harm and injury. In addition, TRPV1 represents a major player in pathological pain arising from inflamed and injured tissues, i.e. inflammatory pain [14,20]. During inflammation, manifold signaling pathways and inflammatory mediators (the so-called "inflammatory soup") can cause aberrant activity of peripheral neurons, and ultimately hypersensitivity to innocuous stimuli (for review see [114]). Examples include diverse amines, growth factors, prostaglandins, chemokines, as well as ATP and protons [114]. Importantly, many of these have been shown to converge onto and sensitize TRPV1 (for review see [82]), rendering it a promising target for novel analgesics (for reviews see $[80,103])$. Hence, considerable effort has been invested into blocking TRPV1 function by antagonists. First generation TRPV1 antagonists, however, interfere with its physiological function and thus, are limited in their therapeutic use $[31,80,103]$. Recent developments are 
therefore concentrated on modality-specific antagonists aimed at targeting selective TRPV1 activation modes [11,30,63,87].

Pathological sensitization of TRPV1 is characterized by reduced activation thresholds and heightened responsiveness [82]. Mechanistically, diverse processes may be at play, such as alterations of (i) channel kinetics, (ii) TRPV1 levels at the neuronal plasma membrane, and (iii) proteins which bind and regulate TRPV1 [9,10,12,47,58,70,73,77,112,117]. An interesting alternative to TRPV1 blockage may therefore be to target TRPV1 interaction partners, particularly those that specifically modulate pathological states such as inflammatory pain $[26,28]$. Such a strategy would provide a means to suppress pathological pain whilst leaving nociceptive pain intact. A recent seminal study showed proof of concept that this kind of approach can be successful: Hanack and colleagues demonstrated that the GABA $A_{B 1}$ receptor restricts TRPV1 sensitization without affecting nociceptive pain [35].

Here, we identify the Vesicle transport through interaction with t-SNAREs homolog 1B (Vti1b) protein as a modulator of TRPV1 sensitization during inflammatory pain. In heterologous cells and in cultured DRG neurons Vti1b promotes TRPV1 sensitization upon inflammation without affecting normal TRPV1 function. In line with our in vitro data we demonstrate that, in vivo, virus-mediated knockdown of Vti1b in sensory neurons attenuates thermal hypersensitivity during inflammatory pain, while neither mechanical hypersensitivity nor capsaicin (Caps)induced nociceptive pain are altered. Using a mass spectrometry-based quantitative interactomics approach, we show that (i) Vti1b is less abundant in TRPV1 protein complexes during inflammatory conditions, and (ii) identify numerous novel and pain state-dependent binding partners of TRPV1. Taken together, our work demonstrates the functional significance of targeting protein-protein interactions specific to inflammatory pain, and provides a unique framework for studying the modulation of TRPV1 in physiological and pathological states.

\section{Materials and methods}

\subsection{Reagents and chemicals}

All chemicals and reagents were purchased from Sigma-Aldrich (St. Louis, MO) or Roth (Karlsruhe, Germany) unless otherwise noted.

\subsection{Human Embryonic Kidney (HEK) 293 cell culture and transient transfection with plasmid DNA}

HEK293 cells were maintained in growth medium (DMEM + GlutaMAX supplemented with $10 \%$ fetal bovine serum and $1 \%$ penicillin/streptomycin (ThermoFisher Scientific, Waltham, $\mathrm{MA}$ ) in flasks at $37^{\circ} \mathrm{C}$ with $5 \% \mathrm{CO}_{2}$ and split once a confluency of $\pm 80 \%$ was reached. Transient transfection was done using FuGENE HD transfection reagent (Promega Corp., Fitchburg, WI) according to manufacturer's instructions. 
Plasmids used in this study: rat pcDNA5-TRPV1-YFP (kind gift from Ardem Patapoutian, La Jolla, CA), mouse pCMV6-Vti1b-myc-DDK (OriGene Technologies, Inc., Rockville, MD) and pCMV-Sport6 empty vector (kind gift from Ardem Patapoutian) as a Mock control. The amount of plasmid DNA used for the different downstream applications (see below) was for PLA \& ICC: TRPV1-YFP \& Vti1b-myc-DDK $300 \mathrm{ng}$ each, and for live labeling, electrophysiology \& calcium imaging: TRPV1-YFP \& Vti1b-myc-DDK 200 ng each. The pCMV-Sport6 plasmid was added to standardize DNA amounts across conditions.

Coating of coverslips for different downstream experiments: For ICC, HEK293 cells were plated on Poly-D-Lysine (PDL, $1 \mathrm{mg} / \mathrm{mL}$, Merck Millipore, Darmstadt, Germany) + Laminin (20 $\mathrm{\mu g} / \mathrm{mL}$, ThermoFisher Scientific)-coated coverslips; in case of calcium imaging and electrophysiology on fibronectin $(50 \mu \mathrm{g} / \mathrm{mL})$-coated coverslips; or fibronectin-coated MatTek dishes (MatTek Corporation, Ashland, MA) for live labeling and PLA.

\subsection{Molecular cloning of TRPV1 $\mathrm{N}$-terminal and $\mathrm{C}$-terminal deletion constructs}

To obtain TRPV1 constructs that either lacked a part of the $\mathrm{C}$ - or of the N-terminus, regions of interest were amplified from the rat pCDNA5-TRPV1-YFP vector with the following primers containing restriction sites (i) TRPV1 "N-term", amino acids 1-744, missing the C-terminus:

fwd, GGGGTACCGATGGAGAAATGGGCTAGC, and

rev, GGGGTACCATGGGCAAGGATGACTTCCGG, (ii) TRPV1 “C-term”, amino acids 184-838, missing the N-terminus: fwd, GGGGTACCATGGCCCGGAAGACAGATAGC, and rev, GCTCTAGATCATTTCTCCCCTGGGGCC. The PCR products were digested and inserted into the pCMV-Sport6 empty vector. The TRPV1 truncation constructs largely retained functionality and membrane expression as reported previously [39].

\subsection{Dissociated cultures of lumbar DRG (IDRG) neurons and nucleofection}

Primary cultures of mouse IDRG neurons were done as described before for DRG cultures [76] with the following modifications: For each IDRG culture, 4 Complete Freund's Adjuvant (CFA)- or vehicle-injected wild type mice were sacrificed by $\mathrm{CO}_{2}$-inhalation and only ipsilateral lumbar DRG 1-5 were dissected. The growth medium Hams' F12/DMEM (ThermoFisher Scientific) was supplemented with $10 \%$ horse serum (ThermoFisher Scientific) and $100 \mathrm{ng} / \mathrm{mL}$ NGF (R\&D Systems, Minneapolis, MN). Neurons were plated on PDL (1 mg/mL) and Laminin $(20 \mu \mathrm{g} / \mathrm{mL})$-coated coverslips.

Transient transfection of IDRG neurons with $500 \mathrm{nM}$ AllStar Negative Control siRNA (\#SI03650318, Qiagen, Hilden, Germany) or Vti1b siRNA (FlexiTube GeneSolution \#GS53612, Qiagen) was done via electroporation using the 4D-Nucleofector ${ }^{\text {TM }}$ System (X unit, Lonza AG, Basel, Switzerland) with P3 Primary neuron nucleofector solution with supplement (Lonza AG), program DC104. Afterwards RPMI medium (ThermoFisher Scientific) with low 
calcium was added for recovery and cells were plated on PDL/Laminin-coated coverslips. After a $15 \mathrm{~min}$ recovery period at $37^{\circ} \mathrm{C}, 1 \mathrm{~mL}$ of DMEM/Hams' $\mathrm{F} 12$ + growth factors was added per well. To reduce toxicity, half of the media was refreshed after $2 \mathrm{~h}$ at $37^{\circ} \mathrm{C}, 5 \% \mathrm{CO}_{2}$. Cells were used $72 \mathrm{~h}$ after siRNA transfection in various in vitro assays (see below).

\subsection{Real-time quantitative PCR (qPCR)}

Total RNA was extracted from cell lysates of Vti1b siRNA and negative control siRNA transfected neurons (72 $\mathrm{h}$ after transfection) using the NucleoSpin RNA XS kit (MACHEREYNAGEL, Düren, Germany) according to the manufacturer's instructions. cDNA was reverse transcribed from total RNA using the QuantiTect Reverse Transcription Kit (Qiagen), following recommendations of the manufacturer. The real time $\mathrm{QPCR}$ for comparative gene expression analysis was done on a Lightcycler 480 platform (Roche, Rotkreuz, Switzerland) with SYBR ${ }^{\mathrm{TM}}$ Green fluorescence detection using Power SYBR Green PCR Master Mix (ThermoFisher Scientific). A final melting curve analysis confirmed the specificity of amplified product. The threshold cycle $(\mathrm{Ct})$ values - the cycle number, in which SYBR green fluorescence exceeds the background - were taken were as a measure of initial transcript amount and normalized to the two reference genes, $\beta$-actin (data not shown) and GAPDH.

Primer sequences $\beta$-actin: rev, CAGCTCAGTAACAGTCCGCC;

fwd, GATCAAGATCATTGCTCCTCCTG.

Primer sequences GAPDH: rev, TTACTCCTTGGAGGCCATGT;

fwd, CAATGAATACGGCTACAGCAAC.

Primer sequences Vti1b: rev, TACACCAGACCGACCAGGAT;

fwd, TCTTCGCTCAATGTCCAGAA.

\subsection{Antibodies used in this study}

Primary antibodies $(\mathrm{Ab})$ : rabbit Vti1b, Synaptic Systems, Goettingen, Germany (ICC 1:500, PLA and WB 1:750, IHC 1:200); rat Lamp-1, BD Biosciences, San Jose, CA (ICC 1:500); goat TRPV1, Santa Cruz Biotechnology, Dallas, TX (ICC: 1:100, PLA (DRG) 1:250, (HEK) 1:400, WB 1:200, IHC 1:200); chicken GFP, ThermoFisher Scientific (IHC: 1:500); rabbit TRPV1, alomone labs, Jerusalem, Israel (PLA: 1:400, WB 1:100, ColP $12 \mathrm{ug}$ ), rabbit rat-TRPV1extracellular, alomone (live 1:50); mouse monoclonal c-myc, Santa Cruz (PLA 1:750).

Secondary antibodies were all purchased from ThermoFisher Scientific and dilution used 1:250, except otherwise mentioned. Donkey anti-rabbit AlexaFluor (AF)488; donkey anti-rabbit AF647; donkey anti-goat AF546; donkey anti-goat AF633; donkey anti-chicken AF488, Biotium, Fremont, CA (1:500); goat anti-chicken AF555; donkey anti-rat DyLight 550; donkey anti-goat AF680 (1:8000); donkey anti-rabbit AF680 (1:8000). 


\subsection{Immunocytochemistry (ICC)}

ICC was essentially performed as described previously [76]:

After rinsing of cells, fixation was done for $10 \mathrm{~min}$ at room temperature (RT) with $4 \%$ paraformaldehyde (PFA) in PBS (ThermoFisher Scientific). Subsequently, cells were washed with PBS and incubated with PBS containing $0.4 \%$ TritonX-100 and $5 \%$ donkey serum (DS, dianova, Hamburg, Germany) for $30 \mathrm{~min}$ at RT to permeabilize cells and block unspecific binding of antibodies. Primary Ab were diluted in Ab solution (1\% DS and $0.1 \%$ TritonX-100 in PBS) and incubated overnight at $4^{\circ} \mathrm{C}$. After extensive washing, secondary antibodies coupled to fluorophores were applied for $2 \mathrm{~h}$ at RT. After rinsing thrice with PBS, coverslips were mounted in SlowFade Gold Antifade Medium with 4',6-Diamidino-2-Phenylindole (DAPI, ThermoFisher Scientific).

\subsection{Proximity Ligation Assay (PLA)}

For the detection of close proximity $(\leq 40 \mathrm{~nm}$ ) of TRPV1 and Vti1b in situ PLA [100] was performed as described in [64] and [76] with modifications. Reagents available in the Duolink $®$ In Situ Detection Reagents Orange set were used.

Twenty-four hours after plating and/or transfection of cells on MatTek dishes, cells washed twice with pre-warmed PBS. Cells were fixed with 4\% PFA/PBS for $10 \mathrm{~min}$ and washed extensively with PBS afterwards. Blocking of unspecific Ab-binding was done with PBS containing $0.4 \%$ TritonX-100 and $5 \%$ DS for $2 \mathrm{~h}$ at RT. Primary Ab were diluted in Ab solution and incubated overnight at $4^{\circ} \mathrm{C}$. Cells were washed extensively in Duolink Wash Buffer $A$ (0.01 M Tris, $0.15 \mathrm{M} \mathrm{NaCl}, 0.05 \%$ Tween20; pH 7.4). Respective PLA PLUS and MINUS probes were diluted 1:10 in Ab solution and incubated 20 min at RT prior to addition to cells. Cells were then incubated with PLA probes for $1 \mathrm{~h}$ at $37^{\circ} \mathrm{C}$. Following several washes with Wash Buffer A, PLA probes were ligated (1:5 dilution of Ligation Stock buffer and 1:40 Ligase in $\mathrm{ddH}_{2} \mathrm{O}$ ) for half an hour at $37^{\circ} \mathrm{C}$. Washing was done thrice with $1 \times$ Wash Buffer $A$ for $10 \mathrm{~min}$ each. The rolling circle amplification reaction was carried out for $100 \mathrm{~min}$ at $37^{\circ} \mathrm{C}$. The reaction was stopped by washing twice for 10 min with Wash Buffer $B(0.2 \mathrm{M}$ Tris, $0.1 \mathrm{M} \mathrm{NaCl}, \mathrm{pH} 7.5)$ and twice for 1 min with $0.01 \times$ Wash Buffer $B$, which was subsequently exchanged to PBS for imaging.

\subsection{Live labeling of HEK293 cells}

Live labeling was essentially performed as described [94].Twenty-four hours after TRPV1-YFP and Vti1b-myc-DDK transfection, live HEK293 cells were labeled with antibodies targeting an extracellular domain of rat TRPV1. The Ab were applied 1:50 in standard growth medium, for $20 \mathrm{~min}$ at $37^{\circ} \mathrm{C}$. Cells were rinsed with pre-warmed medium and then incubated with the Donkey anti-rabbit AF546 secondary Ab (1:200 in medium) for 10 min at RT. Afterwards, the 
cells were washed twice with fresh medium and once with PBS, prior to fixation with $2 \%$ PFA/PBS. Cells were immediately imaged. In some cases, live labeling was combined with intracellular staining of Vti1b to verify successful transfection (data not shown): cells were washed $1 x$ with PBS and permeabilized for 30 min with $0.1 \%$ Triton/PBS $+5 \%$ DS. Primary $\mathrm{Ab}$ were incubated overnight at $4^{\circ} \mathrm{C}$ in $5 \%$ DS/PBS. After $5 \times$ washes with PBS, secondary Ab were applied 1:250 for $2 \mathrm{~h}$ at RT in 1\% DS/PBS. Cells were washes $5 \times$ with PBS and imaged.

\subsection{Calcium imaging}

Ratiometric calcium imaging was performed as described before (e.g. [58]) with modifications using an inverted microscope (Zeiss Axio Observer Z1). Transfected IDRG neurons or HEK293 cells were washed $4 \times$ with pre-warmed Assay Buffer $(1 \times$ Hanks' Balanced Salt Solution $\left(1.3 \mathrm{mM} \mathrm{Ca}^{2+}\right.$ ) with $10 \mathrm{mM}$ HEPES, ThermoFisher Scientific) prior to a $60 \mathrm{~min}$ incubation at $37^{\circ} \mathrm{C}$ with $2.5 \mu \mathrm{M}$ Fura-2/AM + 0.04\% Pluronic F-127 Acid (ThermoFisher Scientific) in Assay Buffer. After incubation, cells were washed and transferred to a recording chamber constantly superfused by a gravity-driven system (circa $5 \mathrm{~mL} / \mathrm{min}$ ), and image at RT.

The stimulation protocol comprised 6 pulses of low capsaicin (Caps; 100 nM; P1-P6) each 1 min long and interspersed with 3 min wash outs of Assay Buffer. This was followed by a high Caps pulse $(1 \mu \mathrm{M})$, and an additional ATP pulse $(20 \mu \mathrm{M})$ in case of HEK293 cells. ATP was applied to confirm similar cell viability at the end of the stimulation protocol (data not shown). Stock solutions of agonists (in absolute ethanol) were diluted in Assay Buffer. For experimental series involving the endocytosis inhibitor Dynasore monohydrate (stock solution in DMSO): $5 \mu \mathrm{M}$ Dynasore was added to the Assay Buffer for the $2^{\text {nd }}$ min of the wash out after Caps pulses P5 and during P6.

The fluorophore Fura-2/AM was alternately excited at $340 \mathrm{~nm}$ and $380 \mathrm{~nm}$ with emission acquired at $510 \mathrm{~nm}$, using MetaFluor software (Molecular Devices, San José, CA). Intracellular calcium concentration is expressed as the 340/380 ratio representing the bound/unbound calcium, and was sampled at $0.333 \mathrm{~Hz}$.

Data analysis: A baseline was calculated for each pulse as the mean ratio for $15 \mathrm{~s}$ prior to pulse application. Responders were defined as cells with amplitude values reaching $120 \%$ of the baseline within the time span from stimulus onset until $15 \mathrm{~s}$ before the next stimulation. Within this range, amplitudes were calculated as the maximum 340/380 ratio per responder subtracted by the respective baseline. This allowed for comparison across cells and cultures. Coverslips where more than $20 \%$ of cells appeared unhealthy - determined by a high initial $340 / 380$ baseline and unstable trace recordings - were omitted from analysis. At least two coverslips per condition from three to four independent culture preparations were analyzed. 


\subsection{Electrophysiology}

Whole-cell patch clamp experiments were performed using an EPC10 USB amplifier (HEKA Elektronik, Lambrecht/Pfalz, Germany) and the PatchMaster software (HEKA). Micropipettes were generated from borosilicate glass capillaries (PG10165-4, World Precision Instruments) using a PIP 6 (HEKA) vertical puller. The patch pipette resistance varied between 1.5-3 M $\Omega$. The bath solution contained $160 \mathrm{mM} \mathrm{NaCl}, 2.5 \mathrm{mM} \mathrm{KCl}, 1 \mathrm{mM} \mathrm{MgCl}$, $2 \mathrm{mM} \mathrm{CaCl} 2,10 \mathrm{mM}$ HEPES and $8 \mathrm{mM}$ glucose (adjusted to $\mathrm{pH} 7.4$ with $\mathrm{NaOH}$ ); pipette solution contained $100 \mathrm{mM}$

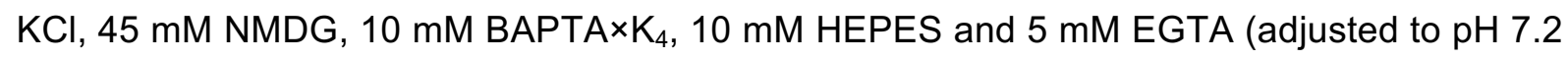
with $\mathrm{NaOH}$ ). YFP-positive HEK293 cells were clamped at their assumed resting potential of - $60 \mathrm{mV}$, capacitance and liquid junction potentials were adjusted and $80 \%$ of the series resistance was compensated. Only cells with low or medium fluorescence levels yielding an initial $\mathrm{G} \Omega$-seal and less than $100 \mathrm{pA}$ leak current were included for further analysis. $500 \mathrm{~ms}$ long linear voltage ramps from -100 to $+100 \mathrm{mV}$ were applied continuously every 5 seconds, held at $+100 \mathrm{mV}$ for $50 \mathrm{~ms}$ and preceded by a voltage step to $-100 \mathrm{mV}$ for $50 \mathrm{~ms}$, in order to record out- and inwardly directed currents, respectively. Whole-cell data was low pass-filtered at $7.9 \mathrm{kHz}$ and collected with a sampling rate of $20 \mathrm{kHz} .100 \mathrm{nM}$ Caps was applied through a gravity-driven application system, with a capillary placed in close proximity to the cell of interest. All experiments were performed at RT. Data were analysed with the FitMaster software (HEKA).

\subsection{Cloning of the AAV6-Vti1b miRNA-EGFP construct and virus production}

The oligonucleotide targeting mouse Vti1b was designed using the BLOCK-iT TM RNAi Designer from ThermoFisher Scientific (https://rnaidesigner.thermofisher.com/rnaiexpress/) and checked for correct folding using the RNAfold WebServer offered by ViennaRNA Web Services (http://rna.tbi.univie.ac.at/cgi-bin/RNAWebSuite/RNAfold.cgi).

The sequence of the Vti1b micro RNA (miRNA), flanked by a BamHI and a HindIII restriction site is $\left(5^{\prime}-3^{\prime}\right)$ :

ggatcctggagg cttgctgaaggctgtatgctgTAGTTTCTCAGCTTAGACATCGTTTTGGCCACTGACT GACGATGTCTACTGAGAAACTAcaggacacaaggcctgttactagcactcacatggaacaaatggcccagatct ggccgcactcgagatatctagacccagctttcttgtacaaagtggttgatatccagcacagtggaagctt.

The oligonucleotide was synthesized and inserted into a pUC57-Kan plasmid via the BamHI and HindIII sites by GenScript Inc. USA (Piscataway, NJ). The AAV6-hSyn-scramble miRNAEGFP construct has been described before [101]. Human Synapsin (hSyn) promotor was used as it allows neuron-specific expression [54]. The scramble miRNA sequence was replaced with the Vti1b miRNA using standard molecular techniques. The production of viral particles was performed as described before [98]. In brief, recombinant AAV6-viruses were propagated in transiently transfected HEK293 cells with pDP6 as the helper plasmid. Viral particles were 
purified by iodixanol step gradient ultracentrifugation followed by affinity chromatography over a heparin column on an Äkta FPLC. Eluted particles were dialyzed extensively against PBS; purity was determined by SDS-PAGE and genome titers by qPCR.

\subsection{Immunohistochemistry (IHC)}

Mice were euthanized by $\mathrm{CO}_{2}$-inhalation, decapitated and IDRG 1-5 dissected - if unilateral treatment of hind paw, ipsilateral (ipsi) and contralateral (con) IDRG were collected separately. After fixation for $3-4 \mathrm{~h}$ in $4 \%$ PFA in PBS at $4^{\circ} \mathrm{C}$, tissue was cryo-protected overnight in $30(\mathrm{w} / \mathrm{v}) \%$ sucrose/PBS at $4^{\circ} \mathrm{C}$. Subsequently, tissue was frozen in Tissue-Tek O.C.T. (Sakura Finetek, Torrance, CA) and tissue blocks stored at $-80^{\circ} \mathrm{C}$ until cutting. Step-serial sections of $10 \mu \mathrm{m}$ thickness were cut with a cryostat (Leica, Wetzlar, Germany), mounted on SuperFrost Plus slides (ThermoFisher Scientific) and stored at $-80^{\circ} \mathrm{C}$.

For the IHC of tissues from AAV6-injected mice: Transcardial perfusions were performed prior to tissue dissection with ice-cold PBS followed by $4 \%$ PFA/PBS. Mice were deeply anesthetized by intraperitoneal application of a Ketamine/Xylazine mixture (100 mg Ketamin + $10 \mathrm{mg}$ Xylazine (medistar, Ascheburg, Germany) per kg bodyweight diluted in sterile PBS). Dissected tissue was post-fixated in $4 \%$ PFA/PBS for $30 \mathrm{~min}$ at $4^{\circ} \mathrm{C}$ and processed as described above.

Frozen sections were thawed at RT for $30 \mathrm{~min}$, and incubated for $30-60 \mathrm{~min}$ with $0.4 \%$ Triton X-100/PBS containing 5\% DS. Next, sections were incubated overnight at $4^{\circ} \mathrm{C}$ with primary antibodies in Ab solution. After extensive washing in PBS, sections were incubated for $2 \mathrm{~h}$ at $\mathrm{RT}$, with the respective secondary antibodies conjugated to Alexa Fluor dyes in Ab solution. Sections were mounted in SlowFade Gold Antifade Medium containing DAPI.

\subsection{Image acquisition and analysis}

For all immunostainings, digital images were acquired on a Zeiss Axio Observer Z1 inverted epifluorescence microscope with Axiovision software (Zeiss, Oberkochen, Germany). The acquisition parameters were kept constant for all experimental groups. Also, secondary Ab controls (no primary $\mathrm{Ab}$ ) were imaged using identical conditions (data not shown). All conditions to be compared were processed concurrently using the same culture or tissue preparation. Raw images were analyzed by using NIH ImageJ [92]. For IHC/ICC: Cells were counted as immuno-label positive if their mean intensity (in arbitrary units) exceeded the mean background intensity $+3 \times$ standard deviation from at least 10 random unstained cells. For $I H C$ (Fig. 1): For the Vti1b stainings the background was determined on sections from Vti1b KO mice that were stained in parallel with the wild type sections, and the calculated background 
from the Vti1b KO also used for the images of the wild type tissue. To avoid double-counting of neurons on cryosections, only sections that were at least $50 \mu \mathrm{m}$ apart were considered.

For ICC (Fig. 3): in addition to the number of positive cells, the integrated intensity was also determined with the "Analyze particle" tool of ImageJ.

For PLA: background intensity was calculated using the signal of three negative cells measured per image to calculate a primary threshold per image. The average of these primary thresholds was taken and used across all images (within each experiment). Cells were traced, and their areas measured (in case of HEK293 cells only YFP-positive cells were considered for analysis). The ratio of PLA signal above threshold/ cell area (per cell) was compared between conditions.

For live labeling experiments: the threshold was calculated per cell, using the unstained area between punctate. YFP-positive cells were traced, and their areas measured. The ratio of TRPV1-extracellular signal above threshold/ cell area (per cell) was compared between conditions.

Only for presentation purposes were brightness \& contrast of matched images adjusted (always in parallel) with ImageJ or Adobe Photoshop CC2017 (Adobe Systems, San José, CA).

\subsection{Animals}

Adult C57BI/6J mice, Trpv1-knockout (TRPV1 KO) B6.129X1-TRPV1 ${ }^{\text {tm1Jul } / J ~(S t o c k \# ~ 003770, ~}$ The Jackson Laboratory), and Vti1b-knockout (Vti1b KO, kind gift from G. Fischer von Mollard, Bielefeld, Germany; [4]), 8-10 weeks old at the time of treatment, were used. Only male mice were used for behavioral experiments. All mouse strains were in-house bred and kept in a temperature- and humidity-controlled environment under a $12 \mathrm{~h}$ light/dark cycle with food and water provided ad libitum. All animal experiments were approved by and carried out in compliance with guidelines of the Landesamt für Verbraucherschutz und Lebensmitte/sicherheit of Lower Saxony (Germany; registration number: Az 16/2079) as well as institutional guidelines. All animal experiments were performed by the same tester, who was blinded to treatment groups.

\subsection{Pain paradigms and behavioral tests}

Intra-sciatic nerve injection of AAV6. For virus-mediated knockdown of Vti1b expression in IDRG neurons, AAV6-Vti1b miRNA-EGFP (as control AAV6-scramble miRNA-EGFP) virus particles were injected into the sciatic nerve. The intranerval injection was performed as described previously [33] with modifications. Mice were randomly assigned to either control or experimental group. The mice received buprenorphine $(0.07 \mathrm{mg} / \mathrm{kg}$, subcutaneous (s.c.), Buprenovet $\AA$, Bayer, Leverkusen, Germany) $15 \mathrm{~min}$ prior to surgery. The surgery was 
performed under isoflurane anesthesia ( $4 \%$ induction, $1.8 \%$ maintenance). The incision area at the left hind leg of the mouse was shaved and disinfected, the sciatic nerve was exposed and $0.9 \times 10^{8}-1.3 \times 10^{9}$ virus particles (in a final volume of $10 \mu \mathrm{L}(2: 1$, PBS: $20(\mathrm{w} / \mathrm{v}) \%$ mannitol) were injected with a $32 \mathrm{G}$ needle attached to a Hamilton syringe over a period of $10 \mathrm{~min}$. Nerve and muscle tissue were repositioned, lidocaine lotion (Xylocain ${ }^{\circ} \mathrm{Gel}$ \% , AstraZeneca, Wedel, Germany) applied onto muscle layer and the skin closed with one surgical clip. Mice received carprofen (5 mg/kg, s.c., Rimadyl®, zoetis, Parsippany-Troy Hills, NJ) 6 h post-surgery.

Mice undergoing virus injections were assessed for their thermal and mechanical sensitivity prior to surgery, $14 / 15$ and 22/23 days after surgery. At day 24, CFA (or vehicle as control) was injected to induce inflammatory pain as described above. Twenty-four hours after CFA injection, mice were tested for thermal hypersensitivity or mechanical hypersensitivity (different cohort) and after $48 \mathrm{~h}$, for mechanical hypersensitivity as described below. At day 28 mice were sacrificed and ipsilateral IDRG 3-5 were isolated and processed for immunohistochemistry (as described above). The cohorts destined for Caps-induced pain behavioral testing were injected with Caps at day 24 after virus-injection and sacrificed the same day for tissue isolation. Only mice that had been successfully transduced, i.e. their IDRG showed GFP expression, were included in the final behavioral data analysis.

Assessment of mechanical sensitivity. Mechanical (hyper-)sensitivity was measured with a Dynamic Plantar Aesthesiometer (\#37450, Ugo Basile, Gemonio, Italy) according to the manufacturer's manual and standard procedures described in [72]. Each mouse was placed in a clear plexiglass compartment with a mesh floor and was allowed to habituate for $2 \mathrm{~h}$. Withdrawal latencies of the hind paws were determined upon application of a graded force (0$10 \mathrm{~g}$ in $40 \mathrm{~s}$ ) to the plantar surface of each hind paw. The time between each stimulus on the same mouse was $2 \mathrm{~min}$, and the average withdrawal latency per paw was calculated. Values that deviated more than $5 \mathrm{~s}$ from the median value per paw of one mouse were excluded. The average paw withdrawal latency per mouse was calculated from at least 3 readings per paw (mice with less than 3 values were excluded from the analysis).

Assessment of thermal sensitivity. To assess heat (hyper-)sensitivity of the hind paw, the Hargreaves' test [36] was conducted using a Plantar Test device (\#37370, Ugo Basile) according to the manufacturer's manual and standard procedures described in [72]. Mice were acclimatized for $2 \mathrm{~h}$ in clear plexiglass compartments on a glass floor. A mobile radiant heat source was then focused onto the plantar surface of each hind paw. The infrared intensity was adjusted so the average withdrawal values of naïve wild type mice were around $10 \mathrm{~s}$. Paw withdrawal latencies were measured with a cut-off time of $30 \mathrm{~s}$, with 2 min between each 
stimulus for a given mouse. The average withdrawal latency per paw was calculated (as described for mechanical sensitivity).

Acute pain - Capsaicin (Caps) injection. To assess acute, TRPV1-mediated pain sensitivity, nocifensive behavior was observed after intraplantar injection (28G Hamilton needle) of Caps $(0.5 \mu \mathrm{g} / \mathrm{paw}$ in $5 \%$ Ethanol/PBS, total volume $10 \mu \mathrm{L})$ into the left hind paw. The duration of nocifensive behaviors - including shaking, lifting, licking or flinching of the paw - over a 6 min period were measured.

Inflammatory pain - Complete Freund's Adjuvant (CFA) injection. Persistent inflammatory pain in the hind paw was induced by intraplantar injection of CFA according to standard procedures [72]. Ten microliters of CFA suspension $(1 \mathrm{mg} / \mathrm{mL}$ cell suspension of heat-killed and dried Mycobacterium tuberculosis) or vehicle (Veh, sterile PBS) were injected intradermally into the hind paw with a 28G Hamilton needle. All CFA-treated animals in this study exhibited pronounced paw edema [72], which was absent in Veh-injected mice.

\subsection{Co-immunoprecipitation (CoIP) of TRPV1}

Freshly dissected ipsilateral IDRG of CFA- and Veh-injected wild type mice (10 mice per biological replicate) and bilateral IDRG from TRPV1 KO mice (5 mice per biological replicate) were used. Three biological replicates per condition were examined, yielding 9 samples to be submitted to mass spectrometric protein identification. All steps were performed on ice or at $4^{\circ} \mathrm{C}$ and all incubation steps under constant agitation. Tissue was homogenized with a glass teflon dounce homogenizer in $500 \mu \mathrm{L} /$ sample solubilization buffer (SB; $0.1 \mathrm{M} \mathrm{NaCl}, 0.05 \mathrm{M}$ Tris- $\mathrm{HCl}, 0.32 \mathrm{M}$ sucrose, $1 \mathrm{mM}$ dithiothreitol (DTT), $1 \% \mathrm{n}$-dodecyl $\beta$-D-maltoside, $1 \times$ complete protease inhibitor cocktail (Roche). Homogenization was supplemented by shearing through a $25 \mathrm{G}$ needle. After solubilisation for $1 \mathrm{~h}$, cell debris was removed by centrifugation at 2,500 $\times \mathrm{g}$ for $10 \mathrm{~min}$. To reduce the unspecific affinity matrix binding, tissue lysates were "precleared" by incubating with $50 \mu \mathrm{L}$ prewashed magnetic Dynabeads Protein G (Thermo Fisher Scientific) for $1 \mathrm{~h}$. After removal of beads, $12 \mu \mathrm{g}$ of rabbit anti-TRPV1 Ab was added and incubated for 4 h. Subsequently, $50 \mu \mathrm{L}$ prewashed Dynabeads Protein $\mathrm{G}$ were added and incubated overnight. Samples were washed once with SB and eluted in $40 \mu \mathrm{L}$ of $1 \times$ Tris-Glycine/SDS Sample Buffer $+1 \mathrm{mM}$ DTT by heating samples to $70^{\circ} \mathrm{C}$ for $10 \mathrm{~min}$.

ColPs from transfected HEK293 cells (not submitted to mass spectrometric protein identification): $24 \mathrm{~h}$ after plating HEK293 cells were transfected with TRPV1-YFP $(4 \mu \mathrm{g} / \mathrm{dish})$ and Vti1b-myc-DDK (4-6 $\mu \mathrm{g} / \mathrm{dish})$ or pCMV-Sport6 (4-6 $\mu \mathrm{g} / \mathrm{dish})$ plasmids using Fugene HD (Promega). The amount of Vti1b-myc-DDK or pCMV-Sport6 was varied from 4-6 $\mu \mathrm{g}$ across replications with no noticeable difference, but remained consistent between conditions for a 
given experiment. pCMV-Sport6 was added to standardise DNA amounts between conditions. Forty-eight hours after transfection, cells were harvested and re-suspended in $500 \mu \mathrm{L} \mathrm{SB}$, for processing as described above. The elution buffer consisted of $1 \times$ LDS Sample Buffer $+1 \times$ Reducing Agent (both ThermoFisher Scientific) in SB.

\subsection{Gel-electrophoresis and Western blot}

All protein samples to be separated by 1D NuPAGE® (Thermo Fisher Scientific) were dissolved in 1× LDS Sample Buffer $+1 \times$ Reducing Agent and had been heated to $70^{\circ} \mathrm{C}$ for 10 min. Proteins loaded into pre-casted NuPAGE® Bis-Tris $4-12 \%$ gradient gels (Thermo Fisher Scientific) were separated by electrophoresis with $1 \times$ NuPAGE $®$ MOPS SDS running buffer (ThermoFisher Scientific; 200 V, 40-50 min). Proteins were transferred to PVDF membranes with the iBlot $₫$ Gel Transfer Device (ThermoFisher Scientific) using program \#3 and a transfer time of $7 \mathrm{~min}$. Western blots were incubated with primary antibodies (diluted in $1 \%$ milk/PBS) for $2 \mathrm{~h}$ at RT and in addition to an overnight incubation at $4{ }^{\circ} \mathrm{C}, 3-5 \times$ diluted. After incubation of respective secondary antibodies for $1 \mathrm{~h}$ at $\mathrm{RT}$, immunolabeled proteins were detected by nearinfrared fluorescence (Odyssey, LI-COR Biosciences, Lincoln, NE).

\subsection{Mass spectrometry (MS) and data analysis}

Sample preparation, data acquisition and data processing

Eluted proteins were separated on pre-casted TG PRiME Tris/glycine 8-16\% gradient gels (SERVA, Heidelberg, Germany) and visualized by colloidal Coomassie staining. Entire gel lanes were cut into 24 equally-sized gel pieces by a self-made punching tool and subjected to automated in-gel digestion with trypsin as described previously [93]. Tryptic peptides were dried down in a vacuum centrifuge, re-dissolved $0.1 \%$ trifluoro acetic acid and spiked with $2.5 \mathrm{fmol} / \mu \mathrm{L}$ of yeast enolase-1 tryptic digest standard (Waters Corporation, Milford, MA) for quantification purposes [99].

Nanoscale reversed-phase UPLC separation of tryptic peptides was performed with a nanoAcquity UPLC system equipped with a Symmetry C18 $5 \mu \mathrm{m}, 180 \mu \mathrm{m} \times 20 \mathrm{~mm}$ trap column and a BEH C18 $1.7 \mu \mathrm{m}, 75 \mu \mathrm{m} \times 100 \mathrm{~mm}$ analytical column (Waters Corporation). Peptides were separated over $60 \mathrm{~min}$ at a flow rate of $300 \mathrm{~nL} / \mathrm{min}$ with a linear gradient of $1-45 \%$ mobile phase $\mathrm{B}$ (acetonitrile containing $0.1 \%$ formic acid) while mobile phase $\mathrm{A}$ was water containing $0.1 \%$ formic acid.

Mass spectrometric analysis of tryptic peptides was performed using a Synapt G2-S quadrupole time-of-flight mass spectrometer equipped with ion mobility option (Waters Corporation). Positive ions in the mass range $\mathrm{m} / \mathrm{z} 50$ to 2000 were acquired with a typical resolution of at least 20,000 FWHM (full width at half maximum) in the ion mobility-enhanced data-independent acquisition (DIA) mode with drift time-specific collision energies $[23,24]$. For 
protein identification, continuum LC-MS data were processed (including lock mass correction) and searched using Waters ProteinLynx Global Server version 3.0.2 [65]. A custom database was compiled by adding the sequence information for yeast enolase 1 and porcine trypsin to the UniProtKB/Swiss-Prot mouse proteome (release 2016_11, 16839 entries) and by appending the reversed sequence of each entry to enable the determination of false discovery rate (FDR). Precursor and fragment ion mass tolerances were automatically determined by PLGS 3.0.2 and were typically below 5 ppm for precursor ions and below 10 ppm (root mean square) for fragment ions. Carbamidomethylation of cysteine was specified as fixed and oxidation of methionine as variable modification. One missed trypsin cleavage was allowed. Minimal ion matching requirements were two fragments per peptide, five fragments per protein, and one peptide per protein. The FDR for protein identification was set to $1 \%$ threshold.

For post-identification analysis, the freely available software ISOQuant (http://www.isoquant.net) was used to merge the 24 LC-MS datasets per gel lane and to calculate the absolute in-sample amounts for each detected protein according to the TOP3 quantification approach [24,55]. The LC-MS datasets from the three biological replicates per condition were included into the same ISOQuant analysis to facilitate cross-annotation of feature clusters, while each of the three conditions was analyzed separately and the data were merged afterwards to prevent inappropriate feature matching between the individual, highly diverse interactomes. The criteria for reporting a protein were as follows: only peptides with a minimum length of six amino acids, an identification score above or equal to 5.5 , and a peptide FDR $<1 \%$ were considered, and only proteins with a minimum of two peptides identified (at least one unique) and a protein FDR $<1 \%$ were quantified. Please see Supplemental Digital Content 1 for a table with details on all quantified proteins.

Data analysis for defining specific TRPV1 interactors. Further data analysis was done with Microsoft Excel and the freely available Perseus software (v1.5.6.0.; [110]): The output lists generated by ISOQuant were merged (1413 proteins) and were filtered for proteins exhibiting a PLGS score of at least 800 (overall score range observed: 171-73431; average score observed: 5722) in one of the groups, yielding 1089 proteins. Protein abundances in each CFA sample were normalized using the ratio of TRPV1 $1_{\text {CFA }}$ to TRPV1 $1_{\text {veh }}$ amounts for each sample pair. The data were uploaded to Perseus and the abundance values (in amol) were $\log _{2^{-}}$ transformed. They were plotted against each other for calculation of the Pearson correlation coefficient (Supplemental Digital Content 2). To enable statistical analysis, missing values were imputed with random values taken from a normal distribution simulating low abundance values around the limit of detection of the mass spectrometer ( width $=0.3$, shift $=1.8[35,44]$ ). For identification of significantly enriched proteins in Veh vs. KO control and CFA vs. KO control, group-wide comparison was done using a modified version of the Student's t-test [109] 
with Perseus software. The s0 parameter was set to 1.58 (i.e. proteins need to exhibit a minimal fold change of 3 at the linear scale) and the q-value (permutation-based multiple testing-corrected p-value) cut-off to 0.01 . The outcome was plotted in a volcano plot with a cutoff curve representing $\mathrm{s} 0$ and an FDR of 0.01 . Next, the significantly regulated proteins in CFA and Veh, respectively, were compared and a fold change $\left(\log _{2}(\mathrm{CFA} / \mathrm{Veh})\right)$ was calculated. To define pain-regulated interactions a threshold of a minimum of $\pm 20 \%$ change $(s 0=0.263=$ $\left.\log _{2}(1.2)\right)$ in protein abundance between the groups was set.

The STRING (Search Tool for the Retrieval of Interacting Genes/Proteins [104], https://string$\mathrm{db} . \mathrm{org} /$ ) database was searched and used to retrieve Gene Ontology (GO) terms enriched $($ FDR < 0.05) among regulated proteins between CFA and Veh (settings: confidence level 0.7).

\subsection{Statistical data analysis (except MS data analysis)}

The statistical analyses were carried out using GraphPad Prism 5.01 and 6.01 (San Diego, CA). For the comparison of two groups either the Mann Whitney test (if data were nonGaussian) or unpaired two-sided Student's t-test was used. For comparison of multiple groups either one-way or two-way ANOVA (dependent on number of analyzed variables, followed by either Bonferroni or Holm-Sidak's multiple tests) were performed, or for non-Gaussian data the Kruskal-Wallis test (followed by Dunn's multiple comparison tests) was used. For analysis of population proportions (Responders vs. Non-responders) in calcium imaging, a Fisher's exact test was performed. P-values smaller than 0.05 were considered significant and marked with ${ }^{*}, p<0.05 ;{ }^{* *}, p<0.01$; and ${ }^{* * *}, p<0.001$.

\section{Results}

\subsection{Vti1b is widely expressed in mouse IDRG}

Alterations of TRPV1 trafficking prominently contribute to pathological pain $[12,27,42,58,70,73,117]$. To gain a better molecular understanding of TRPV1 trafficking, we searched the published resource of genes expressed in DRG neurons [106] for potential candidates modulating intracellular traffic. In particular, we looked for proteins involved in exoand endocytotic pathways, which have not yet been functionally investigated in DRG. Among them Vesicle transport through interaction with t-SNAREs homolog 1B, Vti1b, drew specific attention because (i) it is a prominent mediator of endosomal vesicle transport and fusion of lipid bilayers $[3,74,85,86]$, and (ii) we recently reported its mild downregulation $\left(\log _{2}\right.$ fold change $=-0.158$; multiple-testing corrected q-value $=0.005)$ in the membrane proteome of IDRG during inflammatory pain [6]. We confirmed the results of Thakur and colleagues [106] and found that $\mathrm{Vti} 1 \mathrm{~b}$ is expressed in approximately $80 \%$ of all IDRG neurons. There, Vti1 $\mathrm{b}$ was co-expressed with TRPV1 in 70\% of all TRPV1-positive neurons (Fig. 1A, B). Furthermore, 
Vti1b was partially co-localized with Lamp1, a marker for LE and lysosome compartments (Fig. 1C). These results confirmed the previously reported localization of $\mathrm{Vti} 1 \mathrm{~b}$ to LE and lysosomes [78] also in IDRG neurons. This expression pattern was independent of the presence of TRPV1, as both TRPV1-positive and -negative neurons presented with comparable tubular Lamp1-overlapping staining. We note that TRPV1 immuno-labeling showed an even distribution throughout the cytoplasm which made it impossible to conclude any subcellular colocalization of TRPV1 and Vti1b (Fig. 1C).

\subsection{Vti1b prevents tachyphylaxis of heterologously expressed TRPV1}

We then assessed whether Vti1b functionally modulates TRPV1. To this end, we transiently overexpressed TRPV1 with Vti1b, or with mock (empty vector) as control, in the heterologous expression system of HEK293 cells. First, we performed electrophysiological recordings. As expected, we found TRPV1-mediated whole-cell currents to be outwardly rectifying and sensitive to Caps stimulation [13,15,62]. However, upon Vti1b co-expression TRPV1 outward current amplitudes were significantly attenuated (Fig. 2A). This was likely due to reduced expression of TRPV1 at the plasma membrane of HEK cells co-expressing Vti1b, as visualized by live labeling using a TRPV1 antibody against an external epitope (Fig. 2B).

Such a finding could theoretically stem from the limited capacity of co-transfected cells to adequately express and localize proteins upon overexpression [32]. Therefore, we next assessed another, more pathologically relevant parameter of TRPV1 activity: tachyphylaxis, defined as desensitization and reduced activity upon repetitive agonist stimulation. To do so we applied a well-established experimental paradigm consisting of calcium imaging and repetitive stimulation with Caps $[10,35,88]$. We followed a protocol consisting of 6 Caps pulses (P1-P6): As expected, repetitive Caps application induced tachyphylaxis of TRPV1, which we quantified by comparing cellular calcium responses between the first (P1) and sixth pulse (P6). Remarkably, despite smaller responses to P1 (Fig. 2C, D), cells co-expressing Vti1b hardly exhibited tachyphylaxis to repetitive stimulation, i.e. cellular calcium responses to P6 were largely similar to P1 (Fig. 2C, D). This result suggested that Vti1b may counteract TRPV1 tachyphylaxis potentially by promoting processes leading to its sensitization.

\subsection{CFA-induced sensitization of TRPV1 can be attenuated by knockdown of Vti1b}

To examine this possibility in a setting highly relevant for pathological pain, we turned to the Complete Freund's Adjuvant (CFA) model of inflammatory pain [59]. Under inflammatory conditions, multiple signaling pathways converge on TRPV1 and sensitize/modulate its activity, resulting in hypersensitivity of sensory neurons (for reviews see $[43,82]$ ). TRPV1 sensitization has been successfully monitored in cultured neurons of DRG by calcium imaging upon repetitive Caps application [10,35]. We prepared lumbar DRG (IDRG) cultures from mice, 
in which inflammatory pain (CFA) had been induced compared to vehicle-injection controls. In each of these conditions we then examined the role of $V t i 1 b$ by reducing its expression using nucleofection of siRNA, or AllStar Negative Control siRNA as control. Successful knockdown could be confirmed by quantitative PCR (relative Vti1b mRNA level normalized to GAPDH: $17.0 \pm 3.1 \% ; n=5$ independent cultures) and immunocytochemistry (Fig. 3A and Supplemental Digital Content $3 \mathrm{~A}$ ).

Using calcium imaging (Fig. 3B) we observed that the downregulation of $\mathrm{Vti} 1 \mathrm{~b}$ did not cause a statistically significant difference in the percentage of neurons responding to the initial Caps stimulation (P1) when compared to control nucleofection of either the vehicle or the CFA group, (Fig. 3C and 3D). Interestingly, upon control nucleofection the number of responding neurons to P6 in cultures from CFA-treated mice (CFA c) was significantly increased compared to vehicle-treated controls exhibiting tachyphylaxis (Veh c, Fig. 3E). This finding suggests that CFA-mediated sensitization of TRPV1 channels can overcome tachyphylaxis seen in vehicletreated mice after repetitive stimulation. In contrast, cultures from CFA-treated mice transfected with siRNA against Vti1b (CFA si) showed pronounced tachyphylaxis similar to vehicle-treated cultures (Veh si). This is manifested by a significant reduction of the number of responding neurons to P6 (Fig. 3E) upon Vti1b knockdown (CFA si). In addition, response amplitudes to P6 were slightly decreased in these cultures (Fig. 3F).

We reasoned that the described role of $\mathrm{Vti1} b$ in endosomal membrane trafficking may be mechanistically contributing to this effect. Thus, we hypothesized that TRPV1 endocytosis may be increased in the absence of Vti1b thereby limiting the availability of functional TRPV1. If so, the acute inhibition of clathrin-mediated endocytosis by Dynasore could potentially restore CFA-mediated sensitization in neurons where Vti1b was knocked down. Dynasore inhibits dynamins, a group of GTPases that are responsible for the fission of clathrin-coated pits from the plasma membrane [68]. Indeed, application of Dynasore before and during the P6 restored CFA-mediated sensitization with significant effects on both percentage of responders (Fig. 3E) and response amplitudes in Vti1b siRNA-treated neurons (Fig. 3F).

\subsection{In vivo Vti1b knockdown selectively alleviates heat hypersensitivity during inflammatory pain}

Given our in vitro findings on the modulation of TRPV1 activity we speculated that TRPV1dependent behavioral hypersensitivity may be affected in vivo. To test this hypothesis, we used virus-mediated gene transfer to knockdown Vti1b in sensory neurons of adult mice. We cloned different microRNA (miRNA) constructs targeting Vti1b mRNA and coding for GFP into Adenoassociated virus (AAV) 6 (Vti1b miRNA). These were injected into the sciatic nerve and the rate of knockdown was assessed by immunohistochemistry in IDRG cryosections three weeks later (Fig. 4A). Among three tested constructs, we identified one which successfully targeted 
Vti1b: Injection of Vti1b miRNA reduced the expression of Vti1b to approximately $3 \%$ in transduced (GFP-positive) neurons from $70 \%$ in AAV6-scramble miRNA-GFP controls (Scramble miRNA, Fig. 4B). Of note, the rate of transduction was similar among conditions: approximately $15-18 \%$ of all IDRG neurons were visualized by GFP expression (GFP, Fig. 4B). Also, the number of TRPV1-expressing neurons was not changed among conditions $(29 \%$ of all IDRG neurons in both conditions, Fig. 4C). Among those, $28 \%$ were successfully transduced, as indicated by GFP expression (GFP/TRPV1, Fig. 4C).

We then tested basic sensory behavioral responses to thermal and mechanical stimuli. We did not observe any differences in withdrawal behaviors in mice injected with Vti1b miRNA compared to scrambled controls (Fig. 4D; Supplemental Digital Content 4). Our in vitro data postulate that Vti1b modulates inflammation-induced TRPV1 sensitization while leaving normal TRPV1 function to a single stimulation to Caps intact. In vivo, we tested the latter by evaluating acute nocifensive behaviors after a single intraplantar injection of Caps. As predicted, Caps-induced acute nocifensive behaviors were unaffected upon Vti1b knockdown (Fig. 4E). To assess TRPV1 sensitization in vivo, we again used the CFA-model of inflammatory pain. As expected, $24 \mathrm{~h}$ after CFA injection (a time point at which pronounced inflammatory pain measures have been reported [18]), control mice injected with scramble miRNA displayed robust hypersensitivity to a heat stimulus (thermal hyperalgesia, Fig. 4F; Supplemental Digital Content 4) - a process which is known to involve TRPV1 function [14]. Hypersensitivity is reflected by a reduction in the paw withdrawal latency. Remarkably, in mice injected with Vti1b miRNA we observed a significant alleviation of heat hypersensitivity (Fig. 4F; Supplemental Digital Content 4).

These results are in line with our in vitro findings in cultured IDRG neurons and add further evidence to the notion that $\mathrm{Vti} 1 \mathrm{~b}$ is proalgesic and promotes TRPV1 sensitization. To determine any potential general effects on nocifensive behaviors during inflammation, we also assessed the sensitivity to innocuous mechanical stimulation, which is largely independent of TRPV1 $[14,49]$. Interestingly, mechanical hypersensitivity was unchanged by Vti1b miRNA injection $24 \mathrm{~h}$ after CFA injection (Fig. 4G; Supplemental Digital Content 4). The same was observed $48 \mathrm{~h}$ after CFA injection (Supplemental Digital Content 4). These findings suggest that Vti1b preferentially modulates TRPV1-dependent inflammatory pain behaviors. While TRPV1 is a prominent mediator for CFA-induced heat hypersensitivity, many pathways converge onto TRPV1 and other molecules to promote hyperalgesia after inflammation. Therefore, we cannot exclude the possibility that other channels and signaling cascades might also be affected by the knockdown of Vti1b in sensory neurons in vivo.

Nevertheless, our in vivo findings are in line with our cellular assays. Together they support the conclusion that Vti1b prevents hypersensitivity of TRPV1 during inflammation (Fig. 4F) but 
leaves TRPV1 responsiveness to Caps injection and also basic sensory responses unaffected (Fig. 4D, E).

\subsection{Vti1b is a member of the TRPV1 interactome}

Our data suggest that TRPV1 is a target for the proalgesic function of Vti1b. Consequently, Vti1b would be expected to localize in close vicinity of TRPV1. To investigate this in more detail, we employed the proximity ligation assay (PLA). Indeed, PLA indicated the close vicinity of TRPV1 and Vti1b in cultured IDRG neurons, and upon co-transfection in HEK293 cells (Fig. $5 A, B)$. We also attempted to determine which cytoplasmic region of TRPV1 may be essential for its close vicinity to Vti1b. To this end we performed PLA with TRPV1 truncation constructs (N-terminus and C-terminus truncation, respectively), which largely retain functionality and membrane trafficking of full length TRPV1 constructs as reported previously [39]. However, when co-transfected with Vti1b both truncation constructs yielded PLA signals similar to the respective full-length TRPV1 control PLA experiment preventing us to draw any conclusion about the requirement of cytosolic TRPV1 regions (Supplemental Digital Content 5).

To support our PLA data on full-length TRPV1, we additionally performed coimmunoprecipitations with lysates of HEK293 cells co-transfected with TRPV1 and Vti1b. In these experiments Vti1b co-immunoprecipitated with TRPV1, indicating physical binding of both proteins (Fig. 5C). Whether or not Vti1b directly binds TRPV1 or via an intermediate protein cannot be determined by this assay.

We then turned to murine IDRG to (i) perform co-immunoprecipitations on native TRPV1 and Vti1b, and (ii) to test whether the interaction of TRPV1 and Vti1b might be differentially regulated during inflammatory pain, as was recently shown for KchIP3 [107]. We affinitypurified protein complexes containing native TRPV1 from ipsilateral IDRG of wild type mice injected with CFA or vehicle (Veh) $24 \mathrm{~h}$ after the injection. Furthermore, TRPV1 knockout (KO) mice served as controls for unspecific binding. To account for biological variability as well as differences in sample preparation, 3 biological replicates of each condition (CFA, Veh, and KO; CFA and Veh: 30 mice each; KO: 15 mice) were prepared and subjected to gel electrophoretic separation, followed by label-free protein quantification with mass spectrometry (MS) $[35,102]$. TRPV1 was robustly detected (approx. 54\% sequence coverage) in each of the 3 replicates for Veh and CFA (for the full dataset and correlation across replicates please see Supplemental Digital Content 1 and 2). As expected, samples from TRPV1 KO mice, serving as negative controls, did not contain detectable amounts of TRPV1. To identify highconfidence candidates - that is, proteins present in TRPV1-associated protein complexes (henceforth referred to as the TRPV1 interactome) - identified proteins were scrutinized according to stringent criteria: (i) significant enrichment compared to TRPV1 KO by at least three fold, and (ii) a q-value $<0.01$ (please see methods for details). Since the detected 
absolute amount of co-purified proteins depends on the abundance of affinity-purified TRPV1 in each sample, we normalized data to TRPV1 amounts within biological replicates (see methods for details). In total, 93 proteins were significantly identified in the TRPV1 interactome of Veh samples and 71 in CFA samples compared to KO (Supplemental Digital Content 7). Importantly, some of the identified proteins have already been reported to be associated with TRPV1, validating our results, e.g. TRPV2 [34], dynactin subunit 1 [87] (Dctn1) and extended synaptotagmin-1 [30] (Esyt1, Fig. 6A, gene names in blue). Within the TRPV1 interactome 43 proteins were found in both CFA and Veh, including Vti1b $\left(\log _{2}\right.$ fold change $V e h / K O$ of 4.1 ; $\log _{2}$ CFA/KO = 4.43; $q<0.001$; Fig. 6A, B; Supplemental Digital Content 7). Remarkably, the abundance of Vti1b was reduced by approx. $20 \%$ in samples from CFA-injected mice compared to Veh-injected mice $\left(\log _{2}\right.$ CFA/Veh $\left.=-0.32\right)$. This finding is consistent with our recently published dataset on CFA-induced proteome changes in the membrane of IDRG where we observed mild downregulation of Vti1b during inflammatory pain [6]. Thus, our data postulate a downregulation and/or dissociation of Vti1b from TRPV1-associated protein complexes under inflammatory conditions. This may represent an endogenous mechanism to counteract enhanced TRPV1 function in CFA-treated mice as our in vitro results implicate Vti1b in inflammation-induced TRPV1 sensitization (Fig. 3).

\subsection{Novel insights into the inflammation-related TRPV1 interactome}

In addition to Vti1b, several other members of the TRPV1 interactome were differentially enriched in CFA compared to Veh controls, i.e. in CFA samples 69 were downregulated $\left(\log _{2}\right.$ CFA/Veh < -0.263) and 34 upregulated $\left(\log _{2}\right.$ CFA/Veh $>0.263$ ) by at least $20 \%$ (for complete list please see Supplemental Digital Content 8).

Enrichment analysis of Gene Ontology (GO) terms with the web-based Interface STRING [104] showed that up to $23 \%$ (16/69 CFA downregulated ones) and 64\% (22/34 CFA upregulated ones) are associated with diverse GO terms for cellular component (GO-CC) related to membrane, and also membrane protein complex and plasma membrane region (Fig. 6C; for complete list see Supplemental Digital Content 8). Other prominent associations include the GO-CC term actin cytoskeleton and the GO term for biological process (GO-BP) (actin) cytoskeleton organization. Of note, re-modeling of the actin cytoskeleton has previously been linked to different chronic pain types including CFA-induced inflammatory pain $[56,67]$. Interestingly, we observed an enrichment of GO-CC terms late endosome (6/69) and coated vesicle membrane (3/69) specifically among CFA downregulated TRPV1-associated proteins. Both categories include Vti1b. Moreover, GO-BP terms of establishment of protein localization (including Vti1b) and protein localization to membrane were particularly represented among CFA downregulated TRPV1-interactome members. Hence, our enrichment analysis is in line with the crucial role of TRPV1 trafficking for controlling its activity $[12,27,42,58,70,73,117]$. 
Furthermore, the majority of differentially regulated TRPV1-associated proteins identified here are novel candidates, which have not previously been investigated in the peripheral nervous system. For example, the charged multivesicular body protein $4 \mathrm{~b}$ (Chmp4b), a core subunit of the endosomal sorting complex required for transport (ESCRT) III complex [41], was downregulated in inflammatory conditions $\left(\log _{2}\right.$ CFA/Veh = -7.51). The ESCRT machinery regulates the biogenesis of multi vesicular bodies (MVB) [41]. MVB are a special form of endosomes governing the degradation of plasma membrane proteins. Similarly, the unconventional myosin-VIla (Myo7a) was also downregulated upon inflammation $\left(\log _{2}\right.$ CFA/Veh = -4.02). Unconventional myosins have a proposed importance regarding short distance organelle transport due to their motor domain, but more recently, evidence emerged that they act as dynamic tethers for organelles and membrane-associated proteins [116]. Interestingly, Myo7a deficient mice display increased response latencies in the hot plate assay (data available via the International Mouse Phenotyping Consortium [22]). This phenotype may hint towards altered TRPV1 function. However, other thermosensitive TRP ion channels (TRPM3 and TRPA1) also need to be considered [111]. Another example for a scarcely characterized protein upregulated under inflammatory pain is the von Willebrand factor $A$ domain-containing protein 5A (VWA5A, $\log _{2}$ CFA/Veh = 4.46). Interestingly, high-throughput gene expression profiling (accessed via biogps.org, http://biogps.org/\#goto=genereport\&id=67776, [60]) revealed that VWA5A exhibits pronounced expression in murine DRG compared to other tissues such as spinal cord or brain regions (approximately 10-fold). Mice deficient of another member of the von Willebrand factor A domain-containing protein superfamily, the extracellular matrix protein VWA1, display delayed responses to acute thermal pain stimuli, impaired fine motor coordination, and compromised peripheral nerve morphology [2]. Moreover, two FK506-binding proteins (FKBP), FKBP-2 and FKBP-1A, were strongly downregulated in samples from CFA-injected mice ( $\log _{2}$ CFA/Veh $\left(\right.$ FKBP-2) $=-4.83 ; \log _{2}$ CFA/Veh $\left.(F K B P-1 A)=-3.19\right)$. FKBPs are peptidyl-proline isomerases and catalyze the cis/trans isomerization of proline in peptides. Therefore, they can act as regulators of protein folding and activation [50]. For instance, FKBP-1a is a subunit of the ryanodine receptor RyR1. It regulates the gating of the channel and thereby modulates the gain of skeletal muscle excitation-contraction coupling [1,5,8]. Another member of the FKBP family, FKBP-51, has already been linked to chronic pain via modulating glucocorticoid signaling in spinal cord [69].

Finally, and similarly to Vti1b, several differentially enriched members of the TRPV1 interactome identified here are part of the chronic pain-regulated IDRG membrane proteome we described recently [6]. Remarkably, the abundance of some TRPV1 binding partners identified here was altered during inflammatory pain (CFA-model, e.g. SAMM50, ATP2A2), while others were found to be changed during neuropathic pain (spared nerve injury model, 
e.g. SEPT2, DST, COL6A1; Supplemental Digital Content 8). It is tempting to speculate that the latter group might play a role in well-documented expression changes of TRPV1 during neuropathic pain $[45,51,91]$. Based on these findings, future experiments should assess whether and how TRPV1 binding partners identified here may affect TRPV1 expression and function across different chronic pain states.

\section{Discussion}

TRPV1 sensitization critically contributes to nociceptive and persistent pain. However, our knowledge of molecular processes specific for either pain state is sparse despite its high therapeutic importance. Here, we identify Vti1b as a modulator of TRPV1 sensitization during inflammatory pain. In cultured mouse IDRG neurons, Vti1b promotes TRPV1 sensitization upon inflammation without apparent change in normal TRPV1 function. In line with this we demonstrate that virus-mediated knockdown of Vti1b in sensory neurons in vivo selectively attenuates thermal hypersensitivity during CFA-evoked inflammatory pain. Using a mass spectrometry-based quantitative interactomics approach, we show that (i) Vti1b is downregulated in TRPV1 protein complexes upon inflammation, and (ii) reveal pronounced overall changes in the TRPV1 interactome during inflammatory pain. Hence, our work provides novel insights into the modulation of TRPV1, and a unique framework for further translational studies aimed at specifically targeting inflammatory pain.

Among the plethora of proalgesic mediators released upon tissue damage and inflammation, many sensitize TRPV1 activity. In part, this process underlies phenomena of enhanced nociceptor responsiveness during persistent pain such as allodynia and hyperalgesia. Mechanistically, several scenarios might be at play, including the modulation of channel kinetics, and changes in TRPV1 abundance at the plasma membrane $[9,10,12,47,58,70,73,77,112,117]$. The latter is governed by regulated exo- and endocytosis. These processes are largely dependent on SNARE proteins. Indeed, interfering with the action of the SNARE protein SNAP-25 has been reported to prevent exocytosis of TRPV1 in response to certain proinflammatory mediators [12]. Furthermore, the vesicular proteins snapin and synaptotagmin-9 interact with the N-terminus of TRPV1, and mediate the rapid delivery of TRPV1 to the plasma membrane in response to protein kinase $C$ (PKC) phosphorylation [73]. Here, we report a functional and physical interaction of TRPV1 with the SNARE protein Vti1b. We observed that Vti1b overexpression in HEK293 cells diminished TRPV1 tachyphylaxis. Consequently, TRPV1-dependent calcium influx was maintained even after high-impact stimulation i.e. after repetitive pulses of Caps. Upon Vti1b knockdown sensory neurons displayed pronounced tachyphylaxis in CFA-treated mice and failed to show CFA-mediated sensitization. Consistent with the role of Vti1b in intracellular membrane transport, TRPV1 sensitization could be partially restored by addition of the endocytosis inhibitor Dynasore to 
cultures where Vti1b was knocked down. Dynasore is known to inhibit dynamin-dependent membrane invaginations $[53,68]$, such as clathrin- or caveolin-mediated endocytosis.

Despite novel insights provided here, several questions remain open, for instance, the exact mechanism of Vti1b action on TRPV1 during inflammation. A lack of tools did not allow us to directly measure TRPV1 membrane levels in DRG cultures of CFA-injected mice. To date, commercial antibodies suitable for selectively labeling TRPV1 at the membrane are restricted to detect extracellular epitopes of rat TRPV1 (https://www.alomone.com/p/anti-rat-trpv1extracellular/ACC-029), but do not work on murine TRPV1 studied here. Moreover, we could not determine at which step of TRPV1 membrane trafficking Vti1b comes into play. Endocytosed proteins can either undergo retrograde transport to the trans-Golgi network (recycling pathway), or they are destined for degradation via MVB/LE (degradation pathway) [34,84]. In general, SNARE proteins are implicated in membrane fusion at all these steps [17]. While Vti1b can affect both pathways, it is predominantly known to promote LE-LE fusion [3] and heterotypic fusion of LE with lysosomes $[78,85]$. However, its exact functions remain to be elucidated: studies in Vti1b KO mice are limited by compensation via its close family member Vti1a $[4,57]$. We found a partial co-localization of Vti1b with LE and lysosomes in DRG neurons (Fig. 1C) consistent with previous results in other cell types $[29,78,85]$. Interestingly, SanzSalvador et al. reported that the prolonged exposure of Caps (for $20 \mathrm{~min}$ ) caused an initial rapid endocytosis of TRPV1 followed by lysosomal degradation in DRG neurons [90]. Therefore, increased lysosomal degradation may contribute to impaired CFA-mediated sensitization after Vti1b knockdown. Unfortunately, we could not directly assess this possibility experimentally due to technical constraints. Commonly used inhibitors of lysosomes (e.g. leupeptin, a cysteine protease inhibitor, or bafilomycin A, an inhibitor of lysosomal v-ATPase) require long incubation times (e.g. $2 \mathrm{~h}-24 \mathrm{~h}[37,61])$ preventing their use within the short timeframe ( $3 \mathrm{~min}$ ) between two Caps pulses, i.e. between P5 and P6. Nonetheless, from a physiological point of view, we consider the contribution of lysosomal degradation minor given the immediacy of the effect.

While our results provide some evidence for Vti1b to counteract TRPV1 internalization and/or degradation we cannot exclude other modes of action. During high impact stimulation and inflammatory conditions Vti1b may (i) facilitate a rapid replenishment of functional TRPV1 via the aforementioned recycling pathway, as reported for stimulated exocytosis of the proinflammatory cytokine TNFa in macrophages [74], (ii) alter known processes of calciuminduced TRPV1 desensitization, or (iii) directly affect TRPV1 channel kinetics. We intended to critically test the latter, but failed to obtain stable electrophysiological recordings using our 6pulse protocol of high impact stimulation in both HEK293 cells and DRG cultures. 
It is noteworthy that our in vitro data are faithfully replicated in vivo. Virus-mediated knockdown of Vti1b significantly diminished thermal hypersensitivity in the CFA-model, which involves TRPV1 function. Even though thermal hypersensitivity was attenuated (but not prevented) upon Vti1b knockdown, this result is remarkable given that (i) we only target $28 \%$ of TRPV1positive neurons by virus-mediated gene transfer (Fig. 4), and (ii) potential compensation via Vti1a needs to be considered [4,57]. The latter likely accounts for our results on Vti1b KO mice, which displayed normal thermal hypersensitivity upon CFA when compared to wild type littermates (data not shown). Importantly, neither basal sensitivity nor nociceptive pain were affected upon virus-mediated acute knockdown of Vti1b described here. Also, we did not observe alterations in CFA-induced mechanical hypersensitivity, a process which is largely independent of TRPV1, but also note [14,49]. Mechanical and also thermal hypersensitivity are clinically relevant parameters of chronic pain $[40,46]$. However, our results on these reflexive measures should ideally be complemented by behavioral paradigms assessing aspects of non-evoked ongoing pain, such as voluntary wheel running [19,81], paw guarding behavior [25,81], and conditioned place preference $[21,52,79]$. This could also help to decipher to which extent our in vivo results can be explained by targeting the Vti1b-TRPV1 interaction. Besides TRPV1, numerous signaling pathways [89,115] and other ion channels/receptors have been shown to contribute to inflammatory thermal hypersensitivity such as TRPM3 [113], syntaxin-8 and TrkA receptors [16], and prostaglandin E2 receptor EP4 [66]. Any of these or others might also be affected by Vti1b. Nevertheless, our data collectively suggest that $\mathrm{Vti} 1 \mathrm{~b}$ may be relevant for CFA-induced TRPV1 sensitization as summarized in the working hypothesis outlined in Figure 7.

Here, we have used a MS-based interactomics approach to demonstrate the presence of Vti $1 \mathrm{~b}$ in protein complexes associated with native TRPV1 in sensory neurons. Notably, we also uncovered that Vti1b is less abundant in TRPV1 protein complexes of CFA-treated mice compared to Veh-treated ones. This in in line with our in vitro and behavioral data suggesting that downregulation of $\mathrm{Vti1} \mathrm{b}$ may exert an analgesic role. Functional interactomics has become the method of choice to study protein complex constituents in their native cellular environment. Several ion channel complexes in the CNS have been elucidated in this way $[75,96,97]$. Recently, Hanack et al. reported the interaction of the $G_{A B A}$ receptor subunit and several other proteins with TRPV1 using MS-based interactomics [35]. To this end they coimmunopurified TRPV1 from DRG of knock-in mice overexpressing a tagged version of TRPV1 [35]. Another study identified the potassium channel subunit $\mathrm{K}_{\mathrm{v}} \beta_{2}$ as a binding partner of TRPV1 [7]. While these and also our study provide valuable insights into the modulation of TRPV1 by protein-protein interactions (PPI), one cannot deny the obvious: their results differ substantially, showing hardly any overlap in members of the TRPV1 interactome. Several 
differences in experimental design could account for the missing overlap: (i) starting tissue (wild type BI6/J mice in our study vs. tagged TRPV1 knock-in), (ii) sample preparation (diverse protocols for protein solubilization, $[38,95]$ ) and (iii) MS platform used (with known differences in reproducibility $[71,105])$. Therefore, each of these reports - including ours - likely only detects a subset of the TRPV1 interactome. Nonetheless, our study significantly extends our current knowledge of TRPV1-interaction partners: on one hand, we discovered many novel ones. On the other hand, we determine for the first time changes in the TRPV1 interactome during inflammatory pain - examples of which are introduced in the results part (Fig. 6C and Supplemental Digital Content 8).

Collectively, our data on Vti1b demonstrate the utility of identifying differentially regulated TRPV1 interaction partners for targeting TRPV1 function in a pain state-dependent manner. This becomes particularly important given that first generation TRPV1-antagonists and several commonly-used analgesics elicit severe side effects $[80,83,103]$. Thus, pharmacological interference with TRPV1 protein-protein interactions $[26,35,47]$ might complement recent developments on modality-specific TRPV1 antagonists $[11,63,87]$ to probe novel therapeutic strategies. Finally, our work lends confidence that the differential TRPV1 interactome identified here provides a stepping stone to advance our knowledge on the molecular underpinnings of diverse pain states.

\section{Acknowledgments}

We are grateful to Gabriele Fischer von Mollard (University of Bielefeld, Germany) for kindly providing the Vti1b KO mice, and Ardem Patapoutian (TSRI, California, USA for providing rat TRPV1-YFP and pCMV-Sport6 plasmids. Special thanks to Sergej Zeiter and Elena Ciirdaeva (MPI of Experimental Medicine,MPlem, Goettingen, Germany) for excellent technical assistance, to Walter Stühmer and Luis Pardo (both MPlem) for generously providing the electrophysiology equipment, to Dörte Hesse and Lars Piepkorn (both MPlem) for assistance in generating and analyzing the MS data, to the MPlem animal facility and to Meike Hütte (MPlem) for help establishing virus injections. This work was supported by the Emmy NoetherProgram of the Deutsche Forschungsgemeinschaft (SCHM 2533/2-1 to MS) and the Max Planck Society (PhD fellowship to JRS, IMPRS student fellowship to AMB and RA).

The authors declare no conflicts of interest.

Author's contributions: JRS performed/analyzed biochemistry, molecular biology, calcium imaging, immunostainings, behavior, quantitative MS data and helped writing the manuscript; AMB performed calcium imaging, immunostainings and respective data analysis; OJ performed MS experiments and analysis; NM performed electrophysiological recordings and data analysis; RA helped with immunocytochemistry and qPCR; SK provided the virus 
backbone vector and produced the virus particles; DGV helped with project design and electrophysiological data analysis; MS conceived, designed and supervised all parts of the project and wrote the manuscript.

\section{References}

[1] Ahern GP, Junankar PR, Dulhunty AF. Subconductance states in single-channel activity of skeletal muscle ryanodine receptors after removal of FKBP12. Biophys $\mathrm{J}$ 1997;72:146-162.

[2] Allen JM, Zamurs L, Brachvogel B, Schlötzer-Schrehardt U, Hansen U, Lamandé SR, Rowley L, Fitzgerald J, Bateman JF. Mice lacking the extracellular matrix protein WARP develop normally but have compromised peripheral nerve structure and function. J Biol Chem 2009;284:12020-12030.

[3] Antonin W, Holroyd C, Fasshauer D, Pabst S, Fischer von Mollard G, Jahn R. A SNARE complex mediating fusion of late endosomes defines conserved properties of SNARE structure and function. Embo J 2000;19:6453-6464.

[4] Atlashkin V, Kreykenbohm V, Eskelinen E-L, Wenzel D, Fayyazi A, Fischer von Mollard G. Deletion of the SNARE vti1b in mice results in the loss of a single SNARE partner, syntaxin 8. Mol Cell Biol 2003;23:5198-5207.

[5] Avila G, Lee EH, Perez CF, Allen PD, Dirksen RT. FKBP12 binding to RyR1 modulates excitation-contraction coupling in mouse skeletal myotubes. J Biol Chem 2003;278:22600-22608.

[6] Barry AM, Sondermann JR, Sondermann J-H, Gomez-Varela D, Schmidt M. Regionresolved quantitative proteome profiling reveals molecular dynamics associated with chronic pain in the PNS and spinal cord. Front Mol Neurosci 2018;11:259.

[7] Bavassano C, Marvaldi L, Langeslag M, Sarg B, Lindner H, Klimaschewski L, Kress $\mathrm{M}$, Ferrer-Montiel A, Knaus $\mathrm{H}-\mathrm{G}$. Identification of voltage-gated $\mathrm{K}(+)$ channel beta 2 $(K v \beta 2)$ subunit as a novel interaction partner of the pain transducer Transient Receptor Potential Vanilloid 1 channel (TRPV1). Biochim Biophys Acta 2013;1833:3166-75.

[8] Bellinger AM, Reiken S, Dura M, Murphy PW, Deng S-X, Landry DW, Nieman D, Lehnart SE, Samaru M, LaCampagne A, Marks AR. Remodeling of ryanodine receptor complex causes "leaky" channels: A molecular mechanism for decreased exercise capacity. Proc Natl Acad Sci U S A 2008;105:2198-2202.

[9] Bhave G, Zhu W, Wang H, Brasier DJ, Oxford GS, Gereau IV RW. cAMP-dependent protein kinase regulates desensitization of the capsaicin receptor ( VR1 ) by direct 
phosphorylation. Neuron 2002;35:721-731.

[10] Bonnington JK, McNaughton PA. Signalling pathways involved in the sensitisation of mouse nociceptive neurones by nerve growth factor. J Physiol 2003;551:433-446.

[11] Brown W, Leff RL, Griffin A, Hossack S, Aubray R, Walker P, Chiche DA. Safety, Pharmacokinetics, and Pharmacodynamics Study in Healthy Subjects of Oral NEO6860, a Modality Selective Transient Receptor Potential Vanilloid Subtype 1 Antagonist. J Pain 2017;18:726-738.

[12] Camprubí-Robles M, Planells-Cases R, Ferrer-Montiel A. Differential contribution of SNARE-dependent exocytosis to inflammatory potentiation of TRPV1 in nociceptors. FASEB J 2009;23:3722-3733.

[13] Cao E, Cordero-Morales JF, Liu B, Qin F, Julius D. TRPV1 channels are intrinsically heat sensitive and negatively regulated by phosphoinositide lipids. Neuron 2013;77:667-679.

[14] Caterina MJ, Leffler A, Malmberg AB, Martin WJ, Trafton J, Petersen-Zeitz KR, Koltzenburg M, Basbaum Al, Julius D. Impaired nociception and pain sensation in mice lacking the capsaicin receptor. Science 2000;288:306-313.

[15] Caterina MJ, Schumacher MA, Tominaga M, Rosen TA, Levine JD, Julius D. The capsaicin receptor: a heat-activated ion channel in the pain pathway. Nature 1997;389:816-824.

[16] Chen B, Zhao L, Li X, Ji YS, Li N, Xu XF, Chen ZY. Syntaxin 8 modulates the postsynthetic trafficking of the TrkA receptor and inflammatory pain transmission. J Biol Chem 2014;289:19556-19569.

[17] Chen YA, Scheller RH. SNARE-mediated membrane fusion. Nat Rev Mol Cell Biol 2001;2:98-106.

[18] Cobos EJ, Ghasemlou N, Araldi D, Segal D, Duong K, Woolf CJ. Inflammationinduced decrease in voluntary wheel running in mice: a non-reflexive test for evaluating inflammatory pain and analgesia. Pain 2012;153:876-884.

[19] Cobos EJ, Ghasemlou N, Araldi D, Segal D, Duong K, Woolf CJ. Inflammationinduced decrease in voluntary wheel running in mice: A nonreflexive test for evaluating inflammatory pain and analgesia. Pain 2012;153:876-884.

[20] Davis JB, Gray J, Gunthorpe MJ, Hatcher JP, Davey PT, Overend P, Harries MH, Latcham J, Clapham C, Atkinson K, Hughes SA, Rance K, Grau E, Harper AJ, Pugh PL, Rogers DC, Bingham S, Randall A, Sheardown SA. Vanilloid receptor-1 is essential for inflammatory thermal hyperalgesia. Nature 2000;405:183-187.

[21] Davoody L, Quiton RL, Lucas JM, Ji Y, Keller A, Masri R. Conditioned place preference reveals tonic pain in an animal model of central pain. J Pain 2011;12:868874. 
[22] Dickinson ME, Flenniken AM, Ji X, Teboul L, Wong MD, White JK, Meehan TF, Weninger WJ, Westerberg H, Adissu H, Baker CN, Bower L, Brown JM, Brianna Caddle L, Chiani F, Clary D, Cleak J, Daly MJ, Denegre JM, Doe B, Dolan ME, Edie SM, Fuchs H, Gailus-Durner V, Galli A, Gambadoro A, Gallegos J, Guo S, Horner NR, Hsu C wei, Johnson SJ, Kalaga S, Keith LC, Lanoue L, Lawson TN, Lek M, Mark M, Marschall S, Mason J, McElwee ML, Newbigging S, Nutter LMJ, Peterson KA, Ramirez-Solis R, Rowland DJ, Ryder E, Samocha KE, Seavitt JR, Selloum M, SzokeKovacs Z, Tamura M, Trainor AG, Tudose I, Wakana S, Warren J, Wendling O, West DB, Wong L, Yoshiki A, MacArthur DG, Tocchini-Valentini GP, Gao X, Flicek P, Bradley A, Skarnes WC, Justice MJ, Parkinson HE, Moore M, Wells S, Braun RE, Svenson KL, Hrabe de Angelis M, Herault Y, Mohun T, Mallon AM, Mark Henkelman R, Brown SDM, Adams DJ, Kent Lloyd KC, McKerlie C, Beaudet AL, Bucan M, Murray SA, McKay M, Urban B, Lund C, Froeter E, LaCasse T, Mehalow A, Gordon E, Donahue LR, Taft R, Kutney P, Dion S, Goodwin L, Kales S, Urban R, Palmer K, Pertuy F, Bitz D, Weber B, Goetz-Reiner P, Jacobs H, Le Marchand E, El Amri A, El Fertak L, Ennah H, Ali-Hadji D, Ayadi A, Wattenhofer-Donze M, Jacquot S, André P, Birling MC, Pavlovic G, Sorg T, Morse I, Benso F, Stewart ME, Copley C, Harrison J, Joynson S, Guo R, Qu D, Spring S, Yu L, Ellegood J, Morikawa L, Shang X, Feugas P, Creighton A, Penton PC, Danisment O, Griggs N, Tudor CL, Green AL, Icoresi Mazzeo C, Siragher E, Lillistone C, Tuck E, Gleeson D, Sethi D, Bayzetinova T, Burvill J, Habib B, Weavers L, Maswood R, Miklejewska E, Woods M, Grau E, Newman S, Sinclair C, Brown E, Ayabe S, Iwama M, Murakami A. High-throughput discovery of novel developmental phenotypes. Nature 2016;537:508-514.

[23] Distler U, Kuharev J, Navarro P, Levin Y, Schild H, Tenzer S. Drift time-specific collision energies enable deep-coverage data-independent acquisition proteomics. Nat Methods 2014;11:167-70.

[24] Distler U, Kuharev J, Navarro P, Tenzer S. Label-free quantification in ion mobilityenhanced data-independent acquisition proteomics. Nat Protoc 2016;11:795-812.

[25] Djouhri L, Koutsikou S, Fang X, McMulaan S, Lawson S. Spontaneous Pain, both neuropathic and inflammatory, is related to frequency of spontaneous firing in intact Cfiber nociceptors. J Neurosci 2006;26:1281-1292.

[26] Fernández-Carvajal A, Fernandez-Ballester G, Devesa I, González-Ros JM, FerrerMontiel A. New strategies to develop novel pain therapies: Addressing thermoreceptors from different points of view. Pharmaceuticals 2012;5:16-48.

[27] Ferrandiz-Huertas C, Mathivanan S, Wolf CJ, Devesa I, Ferrer-Montiel A. Trafficking of ThermoTRP Channels. Membranes (Basel) 2014;4:525-564.

[28] Fischer MJM, Btesh J, McNaughton PA. Disrupting sensitization of transient receptor 
potential vanilloid subtype 1 inhibits inflammatory hyperalgesia. J Neurosci 2013;33:7407-7414.

[29] Furuta N, Fujita N, Noda T, Yoshimori T, Amano A. Combinational soluble Nethylmaleimide-sensitive factor attachment protein receptor proteins VAMP8 and Vti1b mediate fusion of antimicrobial and canonical autophagosomes with lysosomes. Mol Biol Cell 2010;21:1001-1010.

[30] Garami A, Shimansky YP, Pakai E, Oliveira DL, Gavva NR, Romanovsky AA. Contributions of Different Modes of TRPV1 Activation to TRPV1 Antagonist-Induced Hyperthermia. J Neurosci 2010;30:1435-1440.

[31] Gavva NR, Treanor JJS, Garami A, Fang L, Surapaneni S, Akrami A, Alvarez F, Bak A, Darling M, Gore A, Jang GR, Kesslak JP, Ni L, Norman MH, Palluconi G, Rose MJ, Salfi M, Tan E, Romanovsky AA, Banfield C, Davar G. Pharmacological blockade of the vanilloid receptor TRPV1 elicits marked hyperthermia in humans. Pain 2008;136:202-210.

[32] Gibson TJ, Seiler M, Veitia RA. The transience of transient overexpression. Nat Methods 2013;10:715-721.

[33] Glatzel M, Flechsig E, Navarro B, Klein MA, Paterna JC, Büeler H, Aguzzi A. Adenoviral and adeno-associated viral transfer of genes to the peripheral nervous system. Proc Natl Acad Sci U S A 2000;97:442-447.

[34] Grant BD, Donaldson JG. Pathways and mechanisms of endocytotic recycling. Mol Cell Biol 2009;10:597-604.

[35] Hanack C, Moroni M, Lima WC, Wende H, Kirchner M, Adelfinger L, Schrenk-Siemens K, Tappe-Theodor A, Wetzel C, Kuich PH, Gassmann M, Roggenkamp D, Bettler B, Lewin GR, Selbach M, Siemens J. GABA blocks pathological but not acute TRPV1 pain signals. Cell 2015;160:759-770.

[36] Hargreaves K, Dubner R, Brown F, Flores C, Joris J. A new and sensitive method for measuring thermal nociception in cutaneous hyperalgesia. Pain 1988;32:77-88.

[37] Hausott B, Vallant N, Hochfilzer M, Mangger S, Irschick R, Haugsten EM, Klimaschewski L. Leupeptin enhances cell surface localization of fibroblast growth factor receptor 1 in adult sensory neurons by increased recycling. Eur J Cell Biol 2012;91:129-138.

[38] Helbig AO, Heck AJR, Slijper M. Exploring the membrane proteome--challenges and analytical strategies. J Proteomics 2010;73:868-78.

[39] Hellwig N, Albrecht N, Harteneck C, Schultz G, Schaefer M. Homo- and heteromeric assembly of TRPV channel subunits. J Cell Sci 2005;118:917-28.

[40] Hendiani JA, Westlund KN, Lawand N, Goel N, Lisse J, McNearney T. Mechanical sensation and pain thresholds in patients with chronic arthropathies. J Pain 
2003;4:203-211.

[41] Henne WM, Buchkovich NJ, Emr SD. The ESCRT pathway. Dev Cell 2011;21:77-91.

[42] Holland S, Coste O, Zhang DD, Pierre SC, Geisslinger G, Scholich K. The ubiquitin ligase MYCBP2 regulates transient receptor potential vanilloid receptor 1 (TRPV1) internalization through inhibition of p38 MAPK signaling. J Biol Chem 2011;286:36713680 .

[43] Huang J, Zhang X, McNaughton PA. Inflammatory pain: The cellular basis of heat hyperalgesia. Curr Neuropharmacol 2006;4:197-206.

[44] Hubner NC, Bird AW, Cox J, Splettstoesser B, Bandilla P, Poser I, Hyman A, Mann M. Quantitative proteomics combined with BAC TransgeneOmics reveals in vivo protein interactions. J Cell Biol 2010;189:739-754.

[45] Hudson LJ, Bevan S, Wotherspoon G, Gentry C, Fox A, Winter J. VR1 protein expression increases in undamaged DRG neurons after partial nerve injury. Eur $\mathrm{J}$ Neurosci 2001;13:2105-2114.

[46] Jensen TS, Finnerup NB. Allodynia and hyperalgesia in neuropathic pain: Clinical manifestations and mechanisms. Lancet Neurol 2014;13:924-935.

[47] Jeske NA, Diogenes A, Ruparel NB, Fehrenbacher JC, Henry M, Akopian AN, Hargreaves KM. A-kinase anchoring protein mediates TRPV1 thermal hyperalgesia through PKA phosphorylation of TRPV1. Pain 2008;138:604-616.

[48] Julius D. TRP channels and pain. Annu Rev Cell Dev Biol 2013;29:355-384.

[49] Kanai Y, Hara T, Imai A, Sakakibara A. Differential involvement of TRPV1 receptors at the central and peripheral nerves in CFA-induced mechanical and thermal hyperalgesia. J Pharm Pharmacol 2007;59:733-738.

[50] Kang CB, Hong Y, Dhe-Paganon S, Yoon HS. FKBP family proteins: Immunophilins with versatile biological functions. NeuroSignals 2008;16:318-325.

[51] Kim HY, Park CK, Cho IH, Jung SJ, Kim JS, Oh SB. Differential changes in TRPV1 expression after trigeminal sensory nerve injury. J Pain 2008;9:280-288.

[52] King T, Vera-Portocarrero L, Gutierrez T, Vanderah TW, Dussor G, Lai J, Fields HL, Porreca F. Unmasking the tonic-aversive state in neuropathic pain. Nat Neurosci 2009;12:1364-1366.

[53] Kirchhausen T, Macia E, Pelish HE. Use of dynasore, the small molecule inhibitor of dynamin, in the regulation of endocytosis. Methods Enzymol 2008;438:77-93.

[54] Kügler S, Kilic E, Bähr M. Human synapsin 1 gene promoter confers highly neuronspecific long-term transgene expression from an adenoviral vector in the adult rat brain depending on the transduced area. Gene Ther 2003;10:337-347.

[55] Kuharev J, Navarro P, Distler U, Jahn O, Tenzer S. In-depth evaluation of software tools for data-independent acquisition based label-free quantification. Proteomics 
2015;15:3140-3151.

[56] Kuner R, Flor H. Structural plasticity and reorganisation in chronic pain. Nat Rev Neurosci 2016;18:20-30.

[57] Kunwar AJ, Rickmann M, Backofen B, Browski SM, Rosenbusch J, Schöning S, Fleischmann T, Krieglstein K, Fischer von Mollard G. Lack of the endosomal SNAREs vti1a and vti1b led to significant impairments in neuronal development. Proc Natl Acad Sci U S A 2011;108:2575-2580.

[58] Laínez S, Valente P, Ontoria-Oviedo I, Estévez-Herrera J, Camprubí-Robles M, Ferrer-Montiel A, Planells-Cases R. GABAA receptor associated protein (GABARAP) modulates TRPV1 expression and channel function and desensitization. FASEB J 2010;24:1958-1970.

[59] Larson AA, Brown DR, El-Atrash S, Walser MM. Pain threshold changes in adjuvantinduced inflammation: A possible model of chronic pain in the mouse. Pharmacol Biochem Behav 1986;24:49-53.

[60] Lattin JE, Schroder K, Su Al, Walker JR, Zhang J, Wiltshire T, Saijo K, Glass CK, Hume DA, Kellie S, Sweet MJ. Expression analysis of G Protein-Coupled Receptors in mouse macrophages. Immunome Res 2008;4:1-13.

[61] Lee S, Sato Y, Nixon RA. Lysosomal proteolysis inhibition selectively disrupts axonal transport of degradative organelles and causes an Alzheimer's-like axonal dystrophy. J Neurosci 2011;31:7817-30.

[62] Leffler A, Fischer MJ, Rehner D, Kienel S, Kistner K, Sauer SK, Gavva NR, Reeh PW, Nau C. The vanilloid receptor TRPV1 is activated and sensitized by local anesthetics in rodent sensory neurons. J Clin Invest 2008;118:763-776.

[63] Lehto SG, Tamir R, Deng H, Klionsky L, Kuang R, Le A, Lee D, Louis J, Magal E, Manning BH, Rubino J, Surapaneni S, Tamayo N, Wang T, Wang J, Wang J, Wang W, Youngblood B, Zhang M, Zhu D, Norman MH, Gavva NR. Antihyperalgesic Effects of ( R , E ) -N- ( 2-Hydroxy-2 , 3-dihydro-1H- acrylamide ( AMG8562 ), a Novel Transient Receptor Potential Vanilloid Type 1 Modulator That Does Not Cause Hyperthermia in Rats. J Pharmacol Exp Ther 2008;326:218-229.

[64] Leuchowius KJ, Weibrecht I, Söderberg O. In situ proximity ligation assay for microscopy and flow cytometry. Curr Protoc Cytom 2011:1-15.

[65] Li GZ, Vissers JPC, Silva JC, Golick D, Gorenstein M V., Geromanos SJ. Database searching and accounting of multiplexed precursor and product ion spectra from the data independent analysis of simple and complex peptide mixtures. Proteomics 2009;9:1696-1719.

[66] Lin C, Amaya F, Barrett L, Wang H, Takada J, Samad TA, Woolf CJ. Prostaglandin E2 receptor EP4 contributes to inflammatory pain hypersensitivity. J Pharmacol Exp Ther 
2006;319:1096-1103.

[67] Lu J, Luo C, Bali KK, Xie RG, Mains RE, Eipper BA, Kuner R. A role for Kalirin-7 in nociceptive sensitization via activity-dependent modulation of spinal synapses. Nat Commun 2015;6:1-10.

[68] Macia E, Ehrlich M, Massol R, Boucrot E, Brunner C, Kirchhausen T. Dynasore, a cellpermeable inhibitor of dynamin. Dev Cell 2006;10:839-850.

[69] Maiarù M, Tochiki KK, Cox MB, Annan L V, Bell CG, Feng X, Hausch F, Géranton SM. The stress regulator FKBP51 drives chronic pain by modulating spinal glucocorticoid signaling. 2016;8:1-11.

[70] Meng J, Wang J, Steinhoff M, Dolly JO. TNFa induces co-trafficking of TRPV1/TRPA1 in VAMP1-containing vesicles to the plasmalemma via Munc18-1/syntaxin1/SNAP-25 mediated fusion. Sci Rep 2016;6:21226.

[71] Michalski A, Cox J, Mann M. More than 100,000 detectable peptide species elute in single shotgun proteomics runs but the majority is inaccessible to data-dependent LCMS/MS. J Proteome Res 2011;10:1785-1793.

[72] Minett MS, Quick K, Wood JN. Behavioral measures of pain thresholds. Curr Protoc Mouse Biol 2013;1:383-412.

[73] Morenilla-Palao C, Planells-Cases R, García-Sanz N, Ferrer-Montiel A. Regulated exocytosis contributes to protein kinase $\mathrm{C}$ potentiation of vanilloid receptor activity. $\mathrm{J}$ Biol Chem 2004;279:25665-25672.

[74] Murray RZ, Wylie FG, Khromykh T, Hume DA, Stow JL. Syntaxin 6 and Vti1b form a novel SNARE complex, which is up-regulated in activated macrophages to facilitate exocytosis of tumor necrosis factor alpha. J Biol Chem 2005;280:10478-10483.

[75] Nadal MS, Ozaita A, Amarillo Y, Vega-Saenz De Miera E, Ma Y, Mo W, Goldberg EM, Misumi Y, Ikehara Y, Neubert TA, Rudy B. The CD26-related dipeptidyl aminopeptidase-like protein DPPX is a critical component of neuronal A-type $\mathrm{K}+$ channels. Neuron 2003;37:449-461.

[76] Narayanan P, Sondermann J, Rouwette T, Karaca S, Urlaub H, Mitkovski M, GomezVarela D, Schmidt M. Native Piezo2 interactomics identifies pericentrin as a novel regulator of Piezo2 in somatosensory neurons. J Proteome Res 2016;15:2676-2687.

[77] Numazaki M, Tominaga T, Toyooka H, Tominaga M. Direct phosphorylation of capsaicin receptor VR1 by protein kinase $C \varepsilon$ and identification of two target serine residues. J Biol Chem 2002;277:13375-13378.

[78] Offenhäuser C, Lei N, Roy S, Collins BM, Stow JL, Murray RZ. Syntaxin 11 binds $\mathrm{Vti1} \mathrm{b}$ and regulates late endosome to lysosome fusion in macrophages. Traffic 2011;12:762-773.

[79] Okun A, DeFelice M, Eyde N, Ren J, Mercado R, King T, Porreca F. Transient 
inflammation-induced ongoing pain is driven by TRPV1 sensitive afferents. Mol Pain 2011;7:1-11.

[80] Patapoutian A, Tate S, Woolf CJ. Transient receptor potential channels: targeting pain at the source. Nat Rev Drug Discov 2009;8:55-68.

[81] Pitzer C, Kuner R, Tappe-Theodor A. Voluntary and evoked behavioral correlates in inflammatory pain conditions under different social housing conditions. Pain Reports 2016;1:e564.

[82] Planells-Cases R, Garcìa-Sanz N, Morenilla-Palao C, Ferrer-Montiel A. Functional aspects and mechanisms of TRPV1 involvement in neurogenic inflammation that leads to thermal hyperalgesia. Pflugers Arch Eur J Physiol 2005;451:151-159.

[83] Price TJ, Gold MS. From Mechanism to Cure: Renewing the Goal to Eliminate the Disease of Pain. Pain Med 2017:1525-1549.

[84] Pryor PR, Luzio JP. Delivery of endocytosed membrane proteins to the lysosome. Biochim Biophys Acta - Mol Cell Res 2009;1793:615-624.

[85] Pryor PR, Mullock BM, Bright NA, Lindsay MR, Gray SR, Richardson SCW, Stewart A, James DE, Piper RC, Luzio JP. Combinatorial SNARE complexes with VAMP7 or VAMP8 define different late endocytic fusion events. EMBO Rep 2004;5:590-595.

[86] Qu B, Pattu V, Junker C, Schwarz EC, Bhat SS, Kummerow C, Marshall M, Matti U, Neumann F, Pfreundschuh M, Becherer U, Rieger H, Rettig J, Hoth M. Docking of Lytic Granules at the Immunological Synapse in Human CTL Requires Vti1bDependent Pairing with CD3 Endosomes. J Immunol 2011;186:6894-6904.

[87] Reilly RM, McDonald HA, Puttfarcken PS, Joshi SK, Lewis L, Pai M, Franklin PH, Segreti JA, Neelands TR, Han P, Chen J, Mantyh PW, Ghilardi JR, Turner TM, Voight EA, Daanen JF, Schmidt RG, Gomtsyan A, Kort ME, Faltynek CR, Kym PR. Pharmacology of Modality-Specific Transient Receptor Potential Vanilloid-1 Antagonists That Do Not Alter Body Temperature. J Pharmacol Exp Ther 2012;342:416-428.

[88] Rivat C, Sar C, Mechaly I, Leyris J-P, Diouloufet L, Sonrier C, Philipson Y, Lucas O, Mallié S, Jouvenel A, Tassou A, Haton H, Venteo S, Pin J-P, Trinquet E, CharrierSavournin F, Mezghrani A, Joly W, Mion J, Schmitt M, Pattyn A, Marmigère F, Sokoloff $P$, Carroll P, Rognan D, Valmier J. Inhibition of neuronal FLT3 receptor tyrosine kinase alleviates peripheral neuropathic pain in mice. Nat Commun 2018;9:1042.

[89] Safieh-Garabedian B, Poole S, Allchorne A, Winter J, Woolf CJ. Contribution of interleukin-1 beta to the inflammation-induced increase in nerve growth factor levels and inflammatory hyperalgesia. Br J Pharmacol 1995;115:1265-1275.

[90] Sanz-Salvador L, Andrés-Borderia A, Ferrer-Montiel A, Planells-Cases R. Agonist- 
and Ca2+-dependent desensitization of TRPV1 channel targets the receptor to lysosomes for degradation. J Biol Chem 2012;287:19462-19471.

[91] Schäfers M, Geis C, Svensson Cl, Luo ZD, Sommer C. Selective increase of tumour necrosis factor-alpha in injured and spared myelinated primary afferents after chronic constrictive injury of rat sciatic nerve. Eur J Neurosci 2003;17:791-804.

[92] Schindelin J, Rueden CT, Hiner MC, Eliceiri KW. The ImageJ ecosystem: An open platform for biomedical image analysis. Mol Reprod Dev 2015;82:518-529.

[93] Schmidt C, Hesse D, Raabe M, Urlaub H, Jahn O. An automated in-gel digestion/iTRAQ-labeling workflow for robust quantification of gel-separated proteins. Proteomics 2013;13:1417-1422.

[94] Schmidt M, Dubin AE, Petrus MJ, Earley TJ, Patapoutian A. Nociceptive signals induce trafficking of TRPA1 to the plasma membrane. Neuron 2009;64:498-509.

[95] Schulte U, Müller CS, Fakler B. Ion channels and their molecular environments Glimpses and insights from functional proteomics. Semin Cell Dev Biol 2011;22:132144.

[96] Schulte U, Thumfart JO, Klöcker N, Sailer CA, Bildl W, Biniossek M, Dehn D, Deller T, Eble S, Abbass K, Wangler T, Knaus HG, Fakler B. The epilepsy-linked Lgi1 protein assembles into presynaptic Kv1 channels and inhibits inactivation by Kvb1. Neuron 2006;49:697-706.

[97] Schwenk J, Harmel N, Zolles G, Bildl W, Kulik A, Heimrich B, Chisaka O, Jonas P, Schulte U, Fakler B, Klöcker N. Functional Proteomics Identify Cornichon Proteins as Auxiliary Subunits of AMPA Receptors. Science (80- ) 2009;323:1313-1319.

[98] Shevtsova Z, Malik JMI, Michel U, Bähr M, Kügler S. Promoters and serotypes: targeting of adeno-associated virus vectors for gene transfer in the rat central nervous system in vitro and in vivo. Exp Physiol 2005;90:53-59.

[99] Silva J, Gorenstein M, GZ L, Vissers J, Geromanos S. Absolute quantification of proteins by LCMSE: a virtue of parallel MS acquisition. Mol Cell Proteomics 2006;5:144-156.

[100] Söderberg O, Gullberg M, Jarvius M, Ridderstråle K, Leuchowius K, Jarvius J, Wester K, Hydbring P, Bahram F, Larsson L-G, Landegren U. Direct observation of individual endogenous protein complexes in situ by proximity ligation. Nat Methods 2006;3:9951000.

[101] Sousa-Ferreira L, Garrido M, Nascimento-Ferreira I, Nobrega C, Santos-Carvalho A, Álvaro AR, Rosmaninho-Salgado J, Kaster M, Kügler S, de Almeida PL, Cavadas C. Moderate long-term modulation of neuropeptide $Y$ in hypothalamic arcuate nucleus induces energy balance alterations in adult rats. PLoS One 2011;6:e22333.

[102] Stankova T, Piepkorn L, Bayer TA, Jahn O, Tirard M. SUMO1-conjugation is altered 
during normal aging but not by increased amyloid burden. Aging Cell 2018;17:e12760.

[103] Szallasi A, Sheta M. Targeting TRPV1 for pain relief: limits, losers and laurels. Expert Opin Investig Drugs 2012;21:1351-1369.

[104] Szklarczyk D, Franceschini A, Wyder S, Forslund K, Heller D, Huerta-Cepas J, Simonovic M, Roth A, Santos A, Tsafou KP, Kuhn M, Bork P, Jensen LJ, Von Mering C. STRING v10: Protein-protein interaction networks, integrated over the tree of life. Nucleic Acids Res 2015;43:D447-D452.

[105] Tabb DL, Vega-Montoto L, Rudnick PA, Variyath MA, Ham A-JL, Bunk DM, Kilpatrick LE, Billheimer DD, Blackman RK, Cardasis HL, Carr SA, Clauser KR, Jaffe JD, Kowalski KA, Neubert TA, Regnier FE, Schilling B, Tegeler TJ, Wang M, Wang P, Whiteaker JR, Zimmerman LJ, Fisher SJ, Gibson BW, Kinsinger CR, Mesri M, Rodriguez H, Stein SE, Tempst P, Paulovich AG, Liebler DC, Spiegelman C. Repeatability and reproducibility in proteomic identifications by liquid chromatography_tandem mass spectrometry. J Proteome Res 2010;9:761.

[106] Thakur M, Crow M, Richards N, Davey GI, Levine E, Kelleher JH, Agley CC, Denk F, Harridge SD, McMahon SB. Defining the nociceptor transcriptome. Front Mol Neurosci 2014;7:87.

[107] Tian N-X, Xu Y, Yang J-Y, Li L, Sun X-H, Wang Y, Zhang Y. KChIP3 N-terminal 31-50 fragment mediates its association with TRPV1 and alleviates inflammatory hyperalgesia in rats. J Neurosci 2018;38:1756-1773.

[108] Tominaga M, Caterina MJ, Malmberg AB, Rosen TA, Gilbert H, Skinner K, Raumann BE, Basbaum Al, Julius D. The cloned capsaicin receptor integrates multiple painproducing stimuli. Neuron 1998;21:531-543.

[109] Tusher VG, Tibshirani R, Chu G. Significance analysis of microarrays applied to the ionizing radiation response. Proc Natl Acad Sci U S A 2001;98:5116-21.

[110] Tyanova S, Temu T, Sinitcyn P, Carlson A, Hein MY, Geiger T, Mann M, Cox J. The Perseus computational platform for comprehensive analysis of (prote)omics data. Nat Methods 2016;13:731-40.

[111] Vandewauw I, De Clercq K, Mulier M, Held K, Pinto S, Van Ranst N, Segal A, Voet T, Vennekens R, Zimmermann K, Vriens J, Voets T. A TRP channel trio mediates acute noxious heat sensing. Nature 2018;555:662-666.

[112] Vellani V, Mapplebeck S, Moriondo A, Davis JB, McNaughton PA. Protein kinase C activation potentiates gating of the vanilloid receptor VR1 by capsaicin, protons, heat and anandamide. J Physiol 2001;534:813-825.

[113] Vriens J, Owsianik G, Hofmann T, Philipp SE, Stab J, Chen X, Benoit M, Xue F, Janssens A, Kerselaers S, Oberwinkler J, Vennekens R, Gudermann T, Nilius B, Voets T. TRPM3 is a nociceptor channel involved in the detection of noxious heat. 
Neuron 2011;70:482-494.

[114] Woolf CJ, Ma Q. Nociceptors--noxious stimulus detectors. Neuron 2007;55:353-64.

[115] Woolf CJ, Safieh-Garabedian B, Ma Q-P, Crilly P, Winter J. Nerve growth factor contributes to the generation of inflammatory sensory hypersensitivity. Lett to Neurosci 1994;62:327-331.

[116] Woolner S, Bement WM. Unconventional myosins acting unconventionally. Trends Cell Biol 2009;19:245-252.

[117] Zhang X, Huang J, McNaughton PA. NGF rapidly increases membrane expression of TRPV1 heat-gated ion channels. EMBO J 2005;24:4211-4223. 


\section{Figure Legends}

Figure 1: Co-expression of Vti1b and TRPV1 in IDRG neurons.

(A) Representative immunohistochemistry for TRPV1 and Vti1b on IDRG cryosections from wild type mice. Co-labeled neurons are marked with white asterisks in the inset of the merged image (right lower panel), with TRPV1-expressing neurons in magenta and Vti1b in cyan. Scale bar, $50 \mu \mathrm{m}$.

(B) Quantification of Vti1b and TRPV1 expression in IDRG neurons from wild type and Vti1b $\mathrm{KO}(\mathrm{KO})$ mice. For Vti1b, wild type vs. KO, ${ }^{* * *} \mathrm{p}<0.0001$. TRPV1 expression is unchanged (non-significant, ns). Vti1b in TRPV1-positive neurons (Vti1b/TRPV1), wild type vs. KO, ${ }^{* * *} \mathrm{p}$ $<0.0001$. Neuron counts are indicated in each column; $n=2-3$ mice; Kruskal-Wallis test followed by Dunn's multiple comparison test. Data are represented as mean \pm SEM.

(C) Immunocytochemistry on dissociated mouse IDRG neurons for TRPV1, Vti1b and Lamp1. The white asterisk indicates a TRPV1-positive neuron. Nuclei are visualized by DAPI staining (blue in lower left panel). Both the TRPV1-positive and TRPV1-negative neuron express Vti1b (cyan in overlay) and Lamp1, a marker for late endosomes (magenta in overlay). $\mathrm{N}=$ several coverslips from 2 independent DRG cultures. Scale bar, $15 \mu \mathrm{m}$.

Figure 2: Overexpression of Vti1b in HEK293 cells alters function, surface levels and tachyphylaxis of TRPV1 channels.

(A, left) Peak current density evoked by $100 \mathrm{nM}$ Caps at $+100 \mathrm{mV}$ and $-100 \mathrm{mV}$ in HEK293 cells transfected with TRPV1-YFP + Mock (TRPV1 + Mock, control) and TRPV1-YFP + Vti1bmyc-DDK (TRPV1 + Vti1b), respectively. Cells were held at $-60 \mathrm{mV}$, and currents were measured during $500 \mathrm{~ms}$-long voltage ramps from -100 to $+100 \mathrm{mV}$ during application of 100 $\mathrm{nM}$ Caps. For $+100 \mathrm{mV},{ }^{* * *} \mathrm{p}=0.0003$, and for $-100 \mathrm{mV}, \mathrm{ns}, \mathrm{p}=0.2755$; two-way ANOVA followed by Holm-Sidak's multiple comparisons test. (A, right) Average I-V relationship before (w/o Caps) and after the application of $100 \mathrm{nM}$ Caps. The reversal potential did not differ between conditions. TRPV1 + Mock: $-8.5 \pm 9.7 \mathrm{mV}$ vs. TRPV1 + Vti1b: $-8.2 \pm 5.9 \mathrm{mV}, \mathrm{ns}, \mathrm{p}=$ 0.8961 ; cell count above column; $n=11-13$ independent cultures; unpaired two-sided Student's t-test.

(B) Live labeling of TRPV1 at the plasma membrane. HEK293 cells transiently transfected with either TRPV1 + Mock (control) or TRPV1 + Vti1b were live-labeled with an antibody directed against an extracellular epitope of TRPV1. (B, left) Representative images of TRPV1-YFPpositive cells of either condition. The TRPV1 antibody labeled only the surface population of TRPV1 (TRPV1-extr). Scale bar, $15 \mu \mathrm{m}$. (B, right) Quantification of the fraction of TRPV1positive membrane area (normalized to the total cell area) in YFP-positive cells. ${ }^{* * *} p<0.0001$; cell count above scatter; $n=3$ independent cultures; Mann-Whitney test.

(C) Averaged representative traces (mean \pm SEM) of ratiometric calcium imaging. Depicted are intracellular calcium rises (indicated as a fluorescence ratio 340/380) to 6 consecutive 100 nM Caps pulses (P1-P6) in HEK293 cells transiently transfected with either TRPV1 + Mock (light blue, $n=91$ cells), or TRPV1 + Vti1b (dark blue, $n=27$ cells). Tachyphylaxis, or the missing thereof, becomes apparent when comparing amplitudes of P6 to P1 within one condition as indicated by black vertical bars (TRPV1 + Mock: continuous line; TRPV1 + Vti1 b: dashed line).

(D, left) Stacked bar graphs display the fraction of responders (colored) and non-responders (white) of TRPV1-expressing cells to P1 and P6 in each condition. P1: TRPV1 + Mock vs. TRPV1 + Vti1b, ${ }^{* * *} p<0.0001$. P1 vs. P6: TRPV1 + Mock, ${ }^{* * *} p<0.0001 ;$ TRPV1 + Vti1b, ns, 
$p=0.5411$; count of responders in column; $n=3$ independent cultures; Fisher's exact test. (D, right) Averaged response amplitudes to $\mathrm{P} 1$ and $\mathrm{P} 6$ (measured as peak of fluorescence ratio 340/380 above baseline). P1: TRPV1 + Mock vs. TRPV1 + Vti1b, ${ }^{* * *} p<0.001$. P1 vs. P6: TRPV1 + Mock, ${ }^{* * *} p<0.0001 ;$ TRPV1 + Vti1b, ns, $p=0.2209$; cell count in column; $n=3$ independent cultures; one-way ANOVA followed by Holm-Sidak's multiple comparisons test. Data are represented as mean \pm SEM. All comparisons are ns if not indicated otherwise.

Figure 3: CFA-induced sensitization of TRPV1 can be attenuated by knockdown of Vti1b. (A) Validation of siRNA-mediated knockdown of Vti1b in IDRG cultures. (A, left) Representative images of dissociated IDRG cultures $72 \mathrm{~h}$ after transfection with control or Vti1b siRNA. Neurons were labelled with antibodies against Vti1b and TRPV1. Scale bar, $25 \mu \mathrm{m}$. (A, right) Quantification of effective siRNA-mediated knockdown of Vti1b. ${ }^{* *} p=0.0047$; cell count in columns; $n=3$ independent culture preparations; unpaired Student's t-test.

(B) Representative traces of ratiometric calcium imaging of dissociated IDRG cultures from Veh-/CFA-injected mice, treated with Vti1b siRNA (si) and control siRNA (c), respectively. Six pulses (P1-P6) of 100 nM Caps were applied.

(C) Stacked bar graphs display the fraction of responders (colored) and non-responders (white) to P1. Count of responders in columns; $n=3$ independent cultures; Fisher's exact test.

(D) Response amplitudes (measured as peak of fluorescence ratio 340/380 above baseline) to $P 1$. Cell count in columns; $n=3$ cultures; one-way ANOVA followed by Holm-Sidak's multiple comparisons test.

(E) Stacked bar graphs display the fraction of responders (colored) and non-responders (white) to P6. Veh c vs. CFA c, ${ }^{* * *} p<0.0001$. Veh si vs. CFA si, ns. CFA c vs. CFA si, ${ }^{* *} p=0.0002$. Addition of Dynasore between P5 and P6: CFA si vs. Dynasore CFA si, ${ }^{*} p=0.0146$; count of responders in columns, $n=3-4$ independent cultures, Fisher's exact test.

(F) Response amplitudes (measured as peak of fluorescence ratio 340/380 above baseline) to P6. CFA c vs. CFA si, ${ }^{*} p=0.0349$. CFA si vs. Dynasore CFA si, ${ }^{* *} p=0.001$; cell count in columns; $n=3-4$ cultures; one-way ANOVA followed by Holm-Sidak's multiple comparisons test.

Data in $A, D$ and $F$ are represented as mean \pm SEM. All comparisons are ns if not indicated otherwise.

Figure 4: AAV6-mediated knockdown of Vti1b attenuates thermal hypersensitivity during inflammatory pain.

(A) Immunohistochemistry on IDRG cryosections of mice injected with AAV6-Vti1b miRNAGFP (Vti1b miR, upper panels) and AAV6-scramble miRNA-GFP (Scramble miR, lower panels) reveals successful knockdown of Vti1b (red) in GFP-positive cells (green) of the Vti1b miR group three weeks post virus injection. White asterisks mark exemplary GFP-positive neurons. Scale bar, $50 \mu \mathrm{m}$.

(B) Quantification of (A) to determine the extent of Vti1b knockdown. Scramble miR vs. Vti1b miR: GFP, ns; Vti1b, ${ }^{* *} \mathrm{p}<0.01$; Vti1b/GFP, ${ }^{* * *} \mathrm{p}<0.001$; cell count in columns; in total $\mathrm{N}>$ 2445 neurons from 4 mice ( 3 IDRG/mouse) per condition; one-way ANOVA followed by Bonferroni's multiple comparison tests.

(C) Quantification of immunohistochemistry on IDRG cryosections from Vti1b miR and scramble miR-injected mice labeled for TRPV1 and GFP. All comparisons ns; cell count per 
label in columns; in total $\mathrm{N}>2000$ neurons from 4 mice (3 IDRG/mouse) per condition; oneway ANOVA.

(D) Quantification of the basal sensitivity (measured as paw withdrawal latency) to a radiant heat stimulus (left) or punctuate mechanical pressure (right). Mice were tested prior to virus injection (pre AAV) and three weeks after virus injection (pre CFA). All comparisons ns; $N$ > 10 mice for each group; $n=2$ independent cohorts; Kruskal-Wallis test.

(E) Mice were injected with Vti1b miR or scramble miR followed by assessment of Capsinduced nociceptive pain three weeks later. Naïve wild type mice served as additional controls. Quantification of nocifensive behavior upon intradermal capsaicin injection $(0.5 \mu \mathrm{g})$. The time spent licking, shaking, flinching or lifting the injected hind paw was measured over a period of six minutes. All comparisons $n s ; ~ N>6$ mice per condition; $n=2$ independent cohorts; KruskalWallis test.

(F) Mice were injected with Vti1b miR or scramble miR followed by assessment of CFA-induced inflammatory pain three weeks later. Quantification of hypersensitivity (measured as withdrawal latency) to a radiant heat stimulus $24 \mathrm{~h}$ after CFA injection. Mice injected with Vti1 b miR exhibited significantly less hyperalgesia, ${ }^{*} p=0.0128 ; N=11$ mice per group; $n=2$ independent cohorts; Mann Whitney test.

(G) Mice were injected with Vti1b miR or scramble miR followed by assessment of CFAinduced inflammatory pain three weeks later. Quantification of hypersensitivity (measured as withdrawal latency) to punctuate mechanical pressure $24 \mathrm{~h}$ after CFA injection. All comparisons $n s, p=0.6501 ; N=8-10$ mice per group; $n=2$ independent cohorts; Mann Whitney test. For data $48 \mathrm{~h}$ after CFA injection please see Supplemental Digital Content 4.

For $(D, F, G)$ : Values obtained by stimulating non-injected contralateral (con) paws, and normalization of withdrawal latencies of injected (ipsi) to con paws (ipsi/con in \%) for each individual mouse can be found in Supplemental Digital Content 4.

For all: Data are represented as mean \pm SEM.

Figure 5: TRPV1 and Vti1b are in close proximity in sensory neurons and upon heterologous expression.

(A, left) Proximity Ligation Assay (PLA) with antibodies against TRPV1 and Vti1b reveals their close proximity in cultured IDRG neurons of wild type mice as compared to similarly treated neurons of TRPV1 KO mice. Arrows mark exemplary neurons that show PLA signal in $>20 \%$ of their cell area. Scale bar, $25 \mu \mathrm{m}$. (A, right) Quantification of PLA signal in IDRG neurons derived from wild type and TRPV1 KO mice. Results are represented as $\%$ of cell area with PLA signal above threshold per individual cell. Wild type vs. TRPV1 KO, ${ }^{* * *} p<0.0001$; cell count above scatter; $n=2-3$ independent cultures; Mann Whitney test.

(B, left) PLA with antibodies against myc (Vti1b) and TRPV1 on HEK293 cells transiently transfected with TRPV1-YFP + Vti1b-myc-DDK or TRPV1-YFP + Mock (controls). Scale bar, $15 \mu \mathrm{m}$. (B, right) Quantification of PLA signal. Results are represented as \% of cell area with PLA signal above threshold per individual cell. Only YFP-positive cells were analyzed. ${ }^{* * *} p<$ 0.0001 ; cell count above scatters; $n=3$ independent cultures; Mann Whitney test. Data represented as mean \pm SEM.

(C) Representative immunoblot of co-immunoprecipitation of TRPV1 with Vti1b. HEK293 cells were transiently transfected with TRPV1-YFP + Vti1b-myc-DDK or TRPV1-YFP + Mock and only Mock as controls $(n=5)$. Membranes were probed against TRPV1 (upper panel) and Vti1b (lower panel). TRPV1 was detected in the elute of TRPV1 + Mock and TRPV1 + Vti1btransfected cells. Vti1b was detected only in the input and elute of the TRPV1 + Vti1b co- 
transfected cells. Note, the lower, less intense band in the input of the TRPV1-YFP \& Vti1bmyc-DDK condition (Vti1b probing) is an unspecific band. An image of the whole blot can be found in Supplemental Digital Content 6.

Figure 6: Determination of high confidence members of the TRPV1 interactome.

(A) Volcano plots show the enrichment of proteins for vehicle (Veh) vs. TRPV1 KO (KO, left) and CFA vs. $K O$ (right). The $\log _{2}$ fold change $\left(\log _{2} V e h / K O\right.$ or $\log _{2}$ CFA/KO) is plotted against the negative logarithm of the $p$-values $\left(-\log _{10} p\right.$-value) of the t-tests. The cut-off line is based on an estimation of the FDR by permutation. Proteins to the right of the cut-off line (on the right side of the graph) are considered high confidence interacting proteins (FDR < 0.01). TRPV1 is labeled in green, Vti1 $\mathrm{b}$ is labeled in red, previously detected interactors of TRPV1 are labeled in blue, and novel high confidence interactors that are discussed in the main text are labeled in grey.

(B) Venn diagram summarizes the numbers of identified high confidence interacting proteins in CFA and Veh samples.

(C) Selected gene ontology cellular component (GO-CC) categories and biological process (GO-BP) categories enriched among differentially regulated members of the TRPV1 interactome (FDR < 0.05; assessed via the web-based interface STRING). The complete GO analysis can be found in Supplemental Digital Content 8.

\section{Figure 7: Working hypothesis on the regulation of TRPV1 via Vti1b during CFA-induced inflammatory pain.}

Upon repetitive or prolonged stimulation TRPV1 is known to be internalized, contributing to tachyphylaxis. We show that under inflammatory conditions this tachyphylaxis is largely overridden and instead, TRPV1 sensitization occurs. This likely contributes to heat hypersensitivity in the CFA-model. Upon downregulation of Vti1b TRPV1 endo/exocytosis may be perturbed (as indicated by the partial rescue via Dynasore) potentially leading to a reduction of functional TRPV1 levels at the plasma membrane. Hence, heat hypersensitivity is attenuated. Interestingly, TRPV1 interactomics experiments revealed a reduction of $\mathrm{Vti} 1 \mathrm{~b}$ in TRPV1-associated protein complexes. This might represent an endogenous mechanism of keeping inflammation-induced TRPV1 sensitization in check. Of note, under low-impact stimulation (i.e. a single pulse of Caps, P1) TRPV1 function appears to be independent of Vti1b. 
Figure 1

A

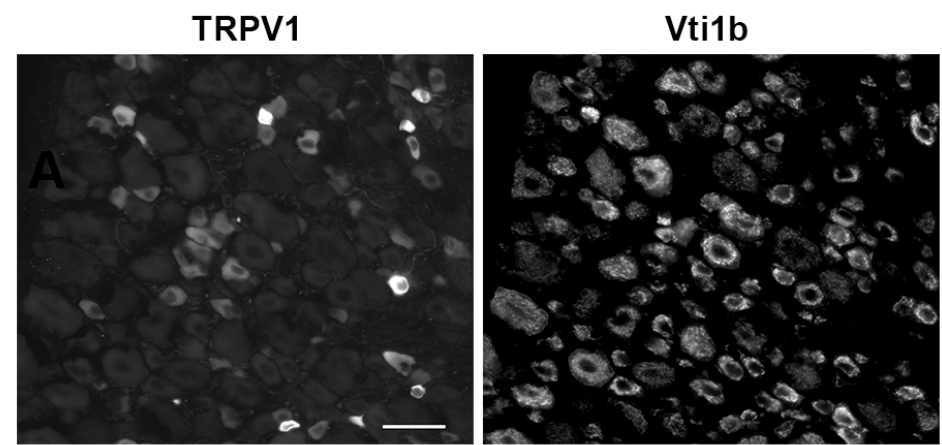

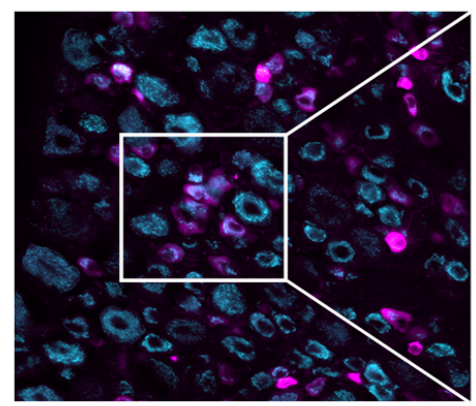

TRPV1 \& Vti1b

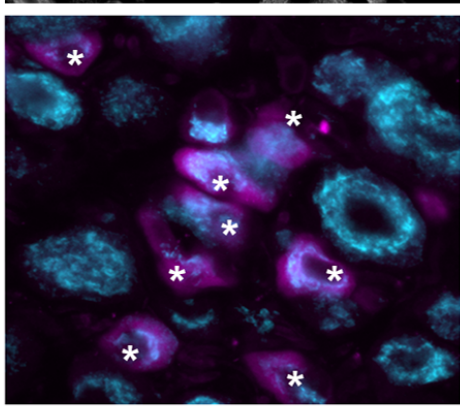

Inset

B

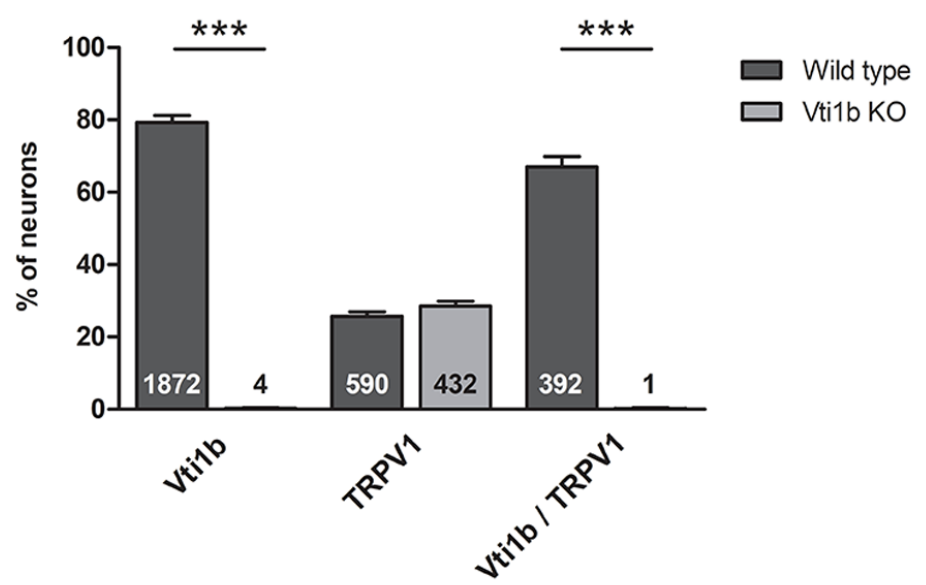

C

Vti1b

Lamp1
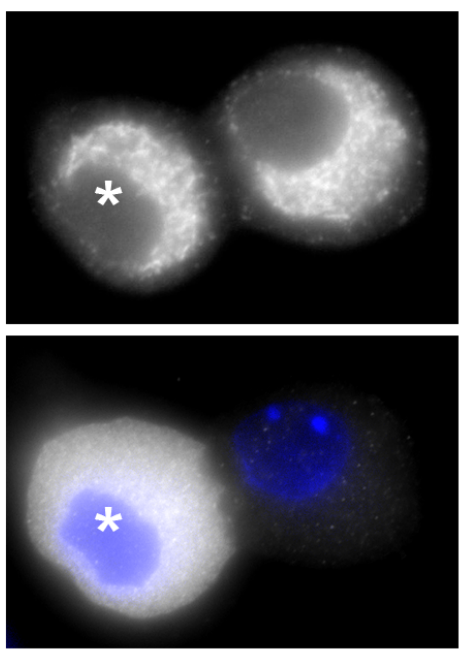

TRPV1 \& DAPI
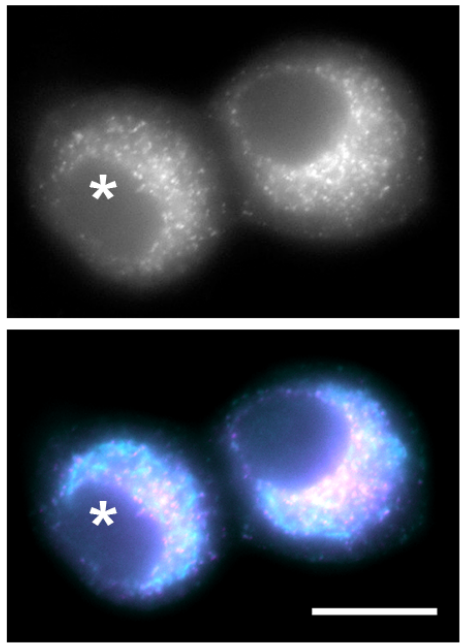

Vti1b \& Lamp1 


\section{Figure 2}

A

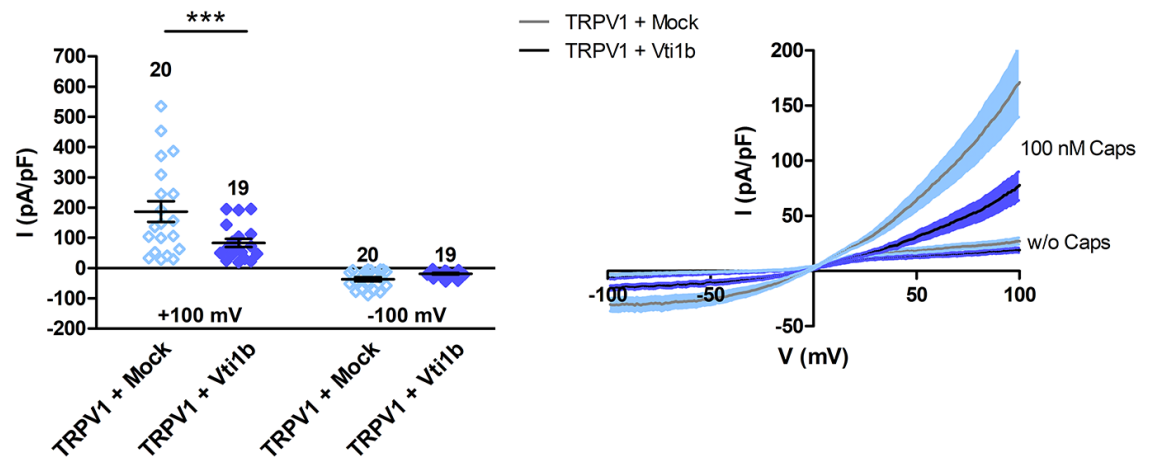

B
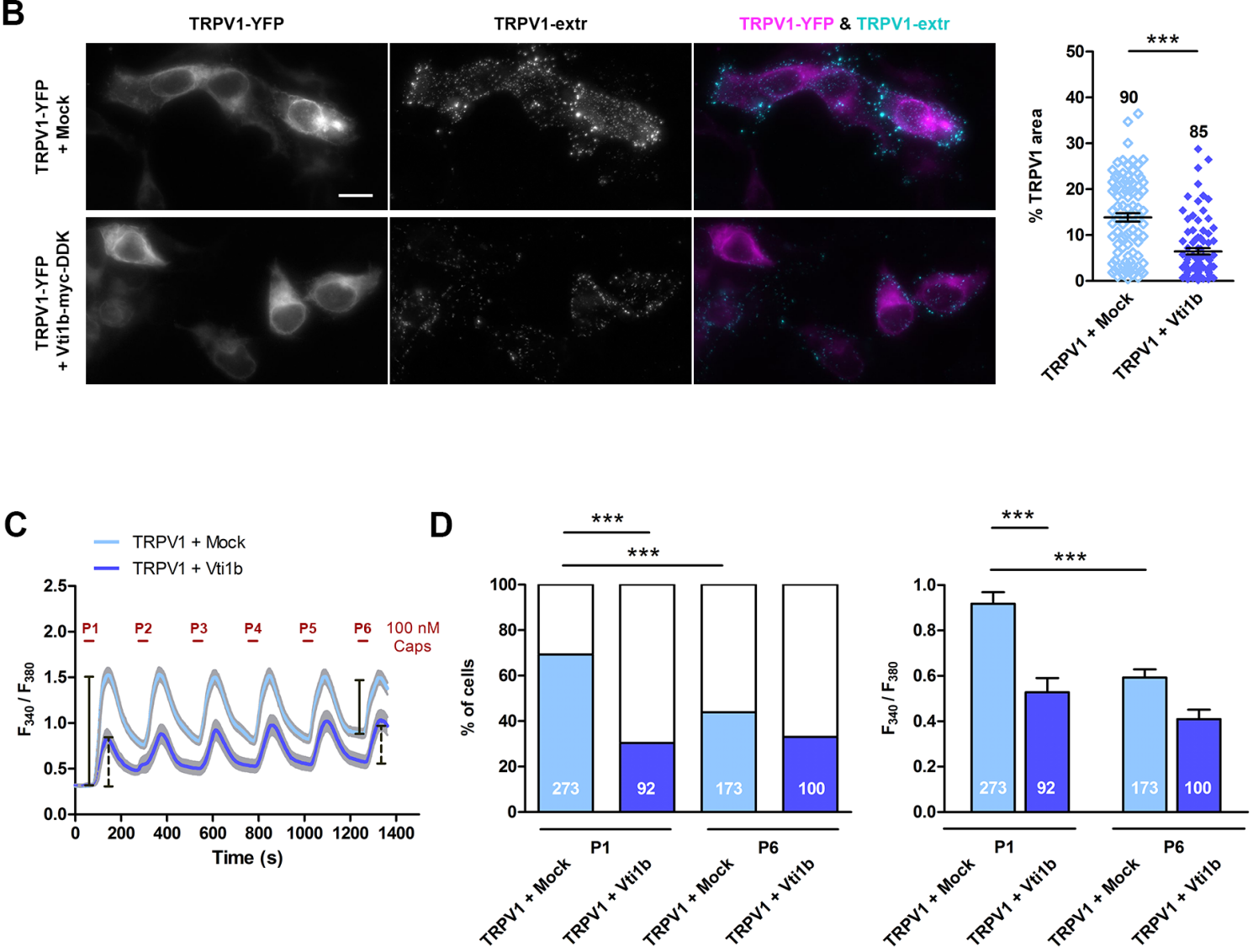
Figure 3

A

A vti1b
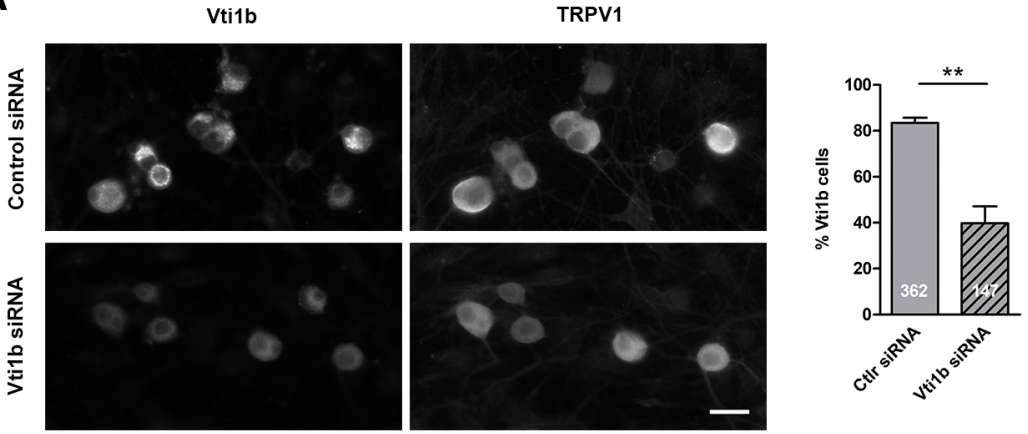

B

Veh - control siRNA

Veh - Vti1b siRNA
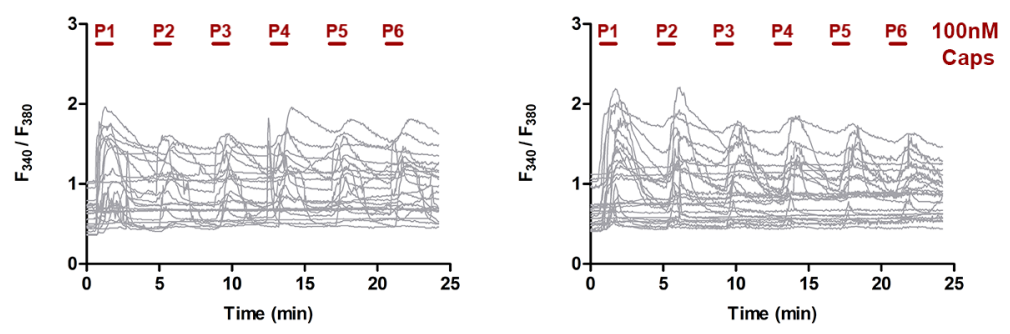

CFA - control siRNA

CFA - Vti1b siRNA
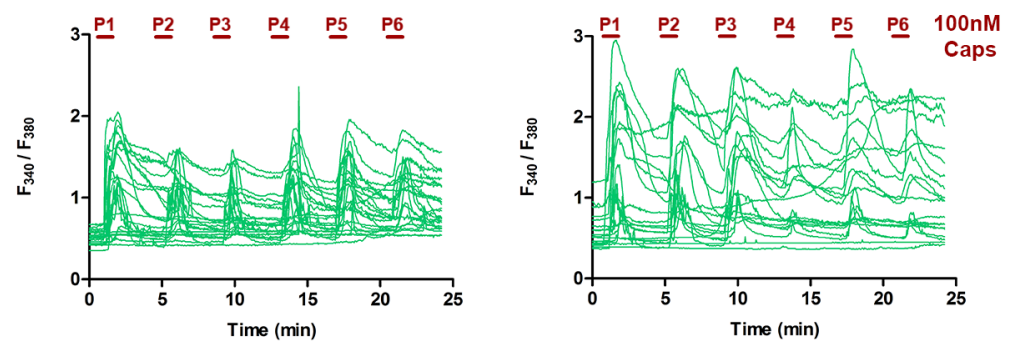

C

D
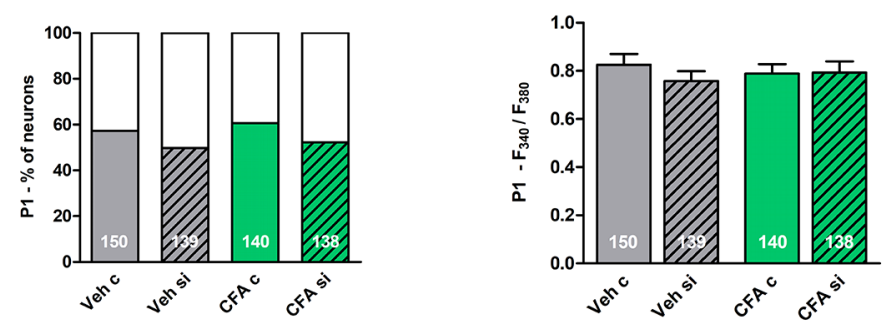

E
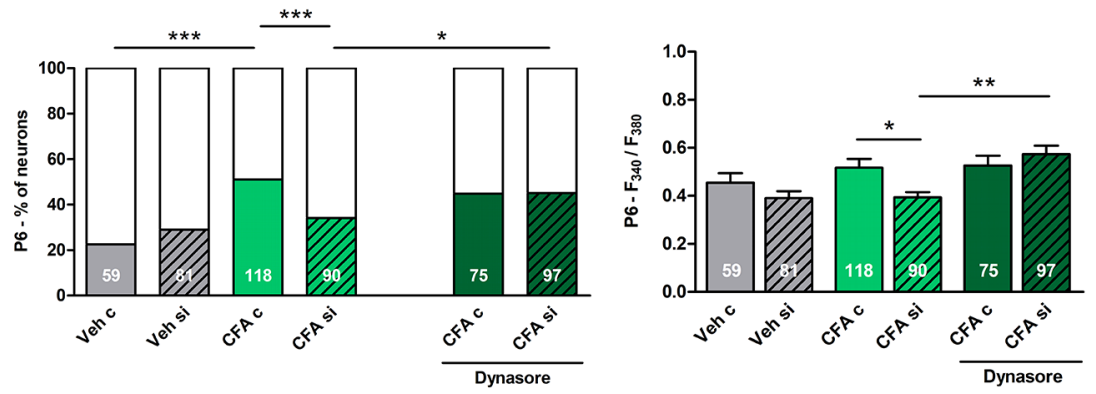


\section{Figure 4}

A
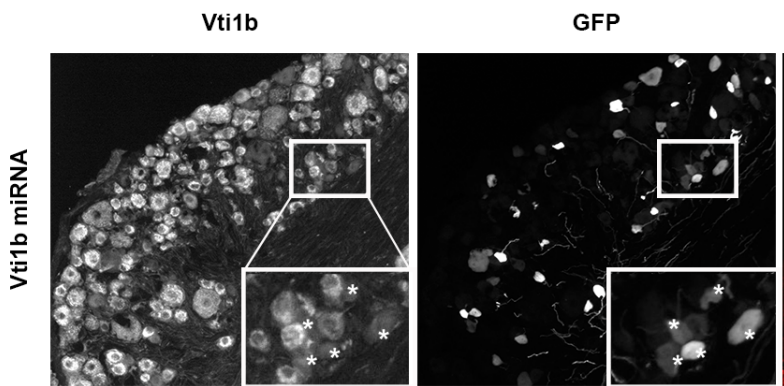

Vti1b \& GFP
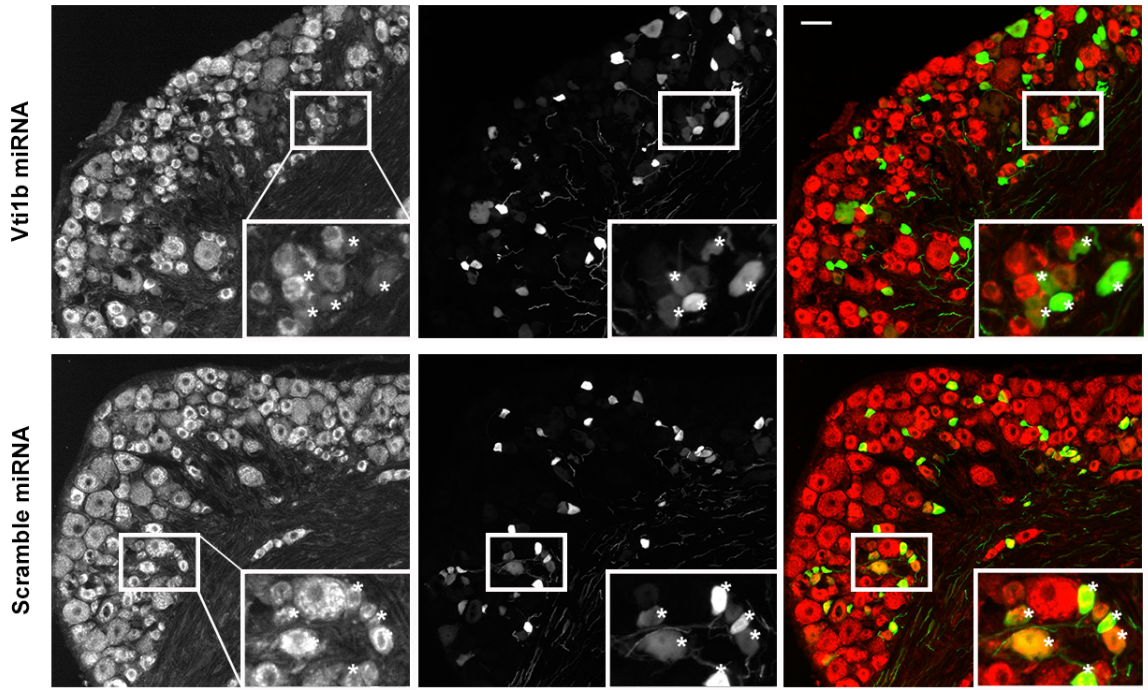

B

C
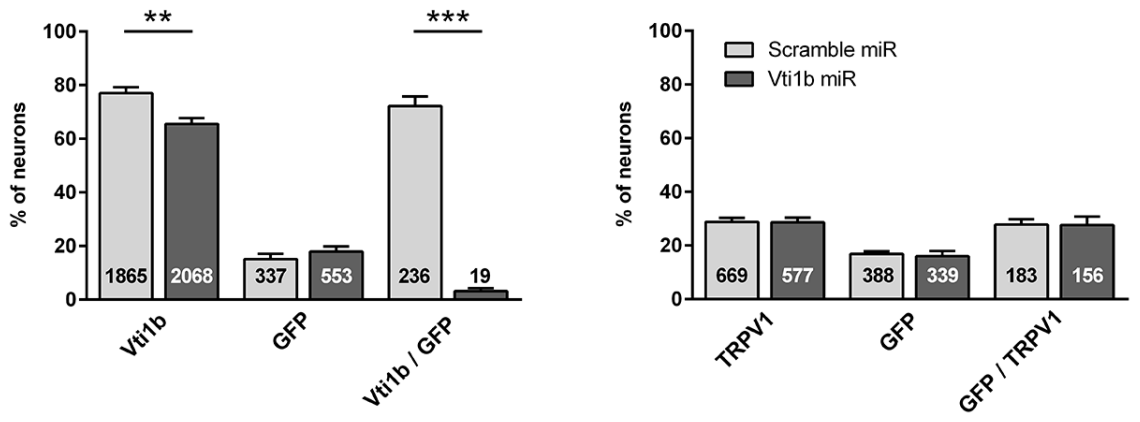

D Pretests - Thermal sensitivity
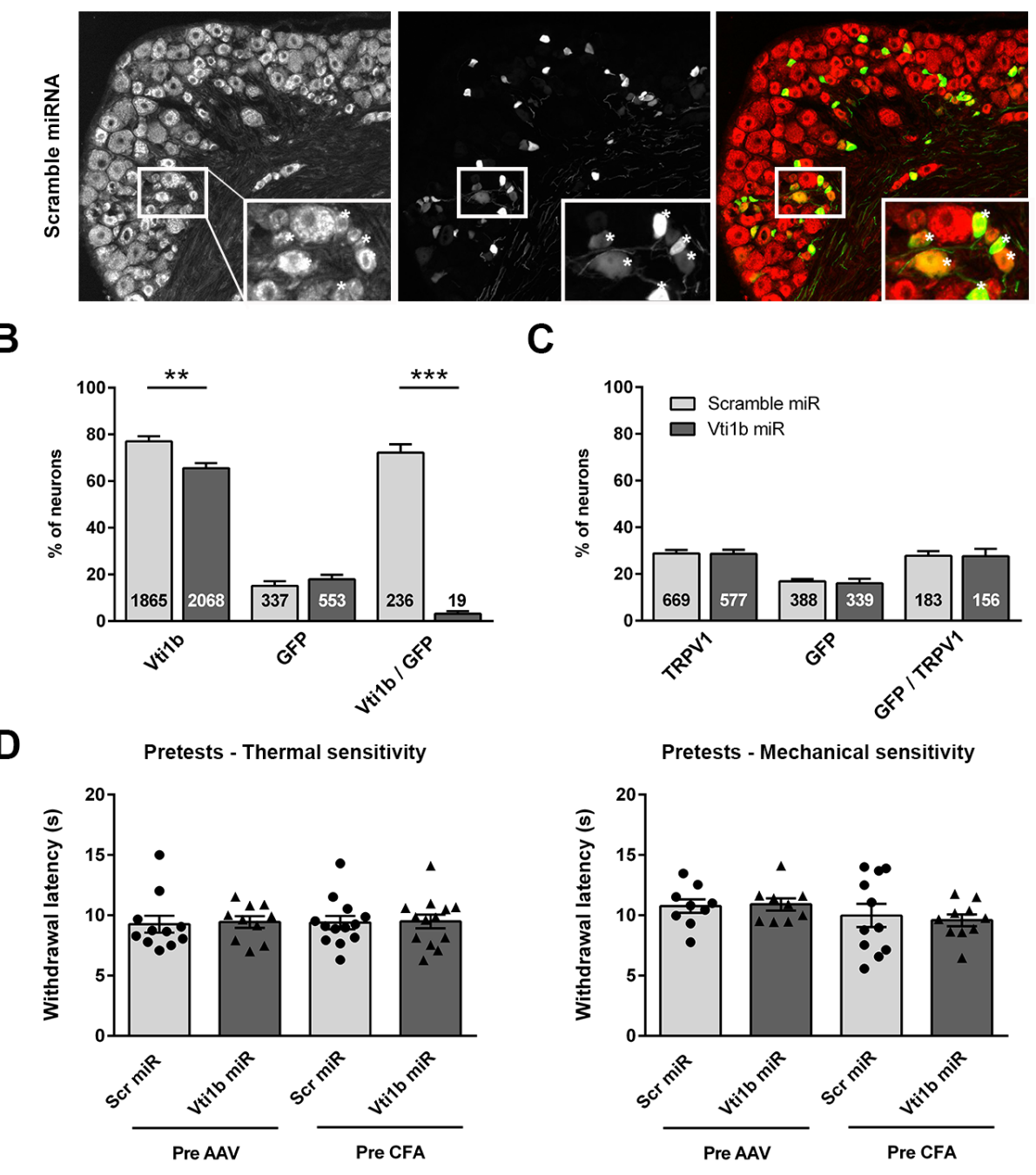

E
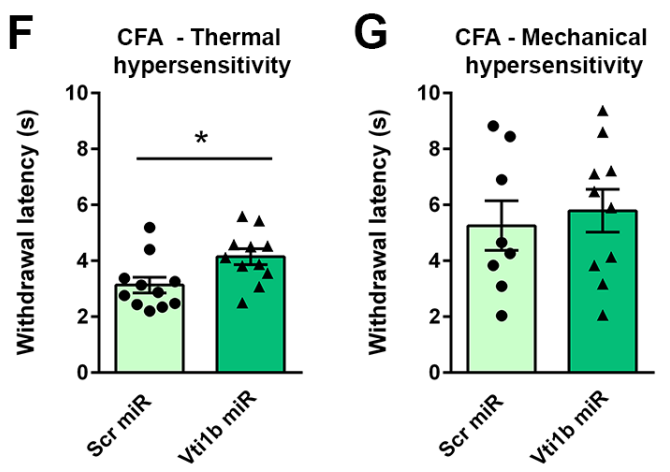


\section{Figure 5}

A
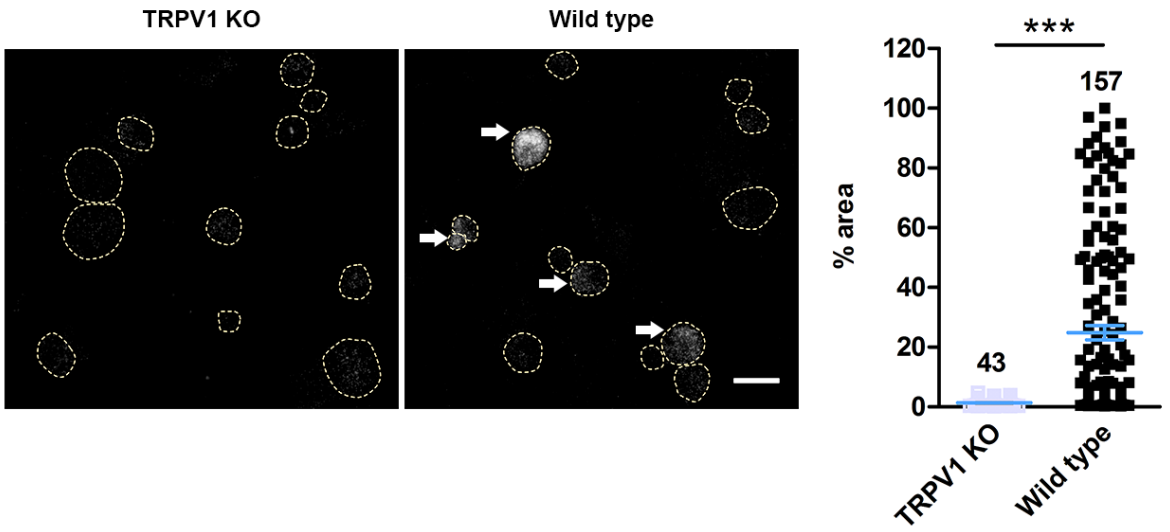

B

TRPV1-YFP
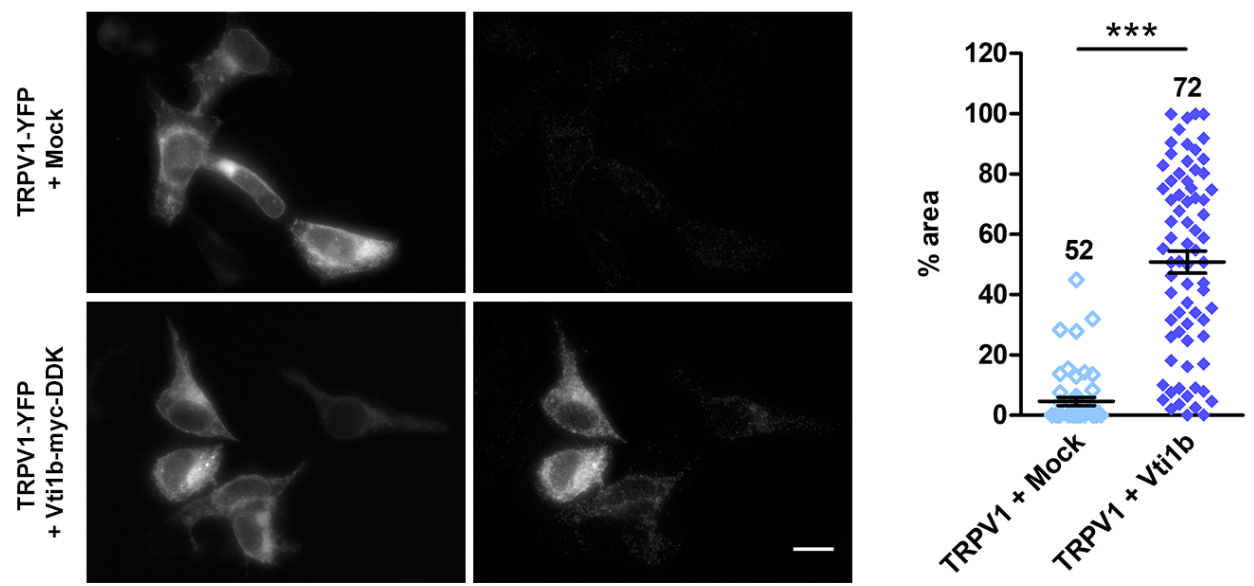

C

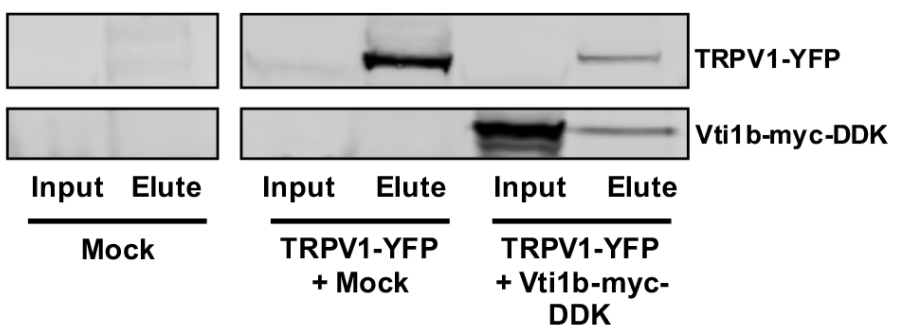


Figure 6

A

B
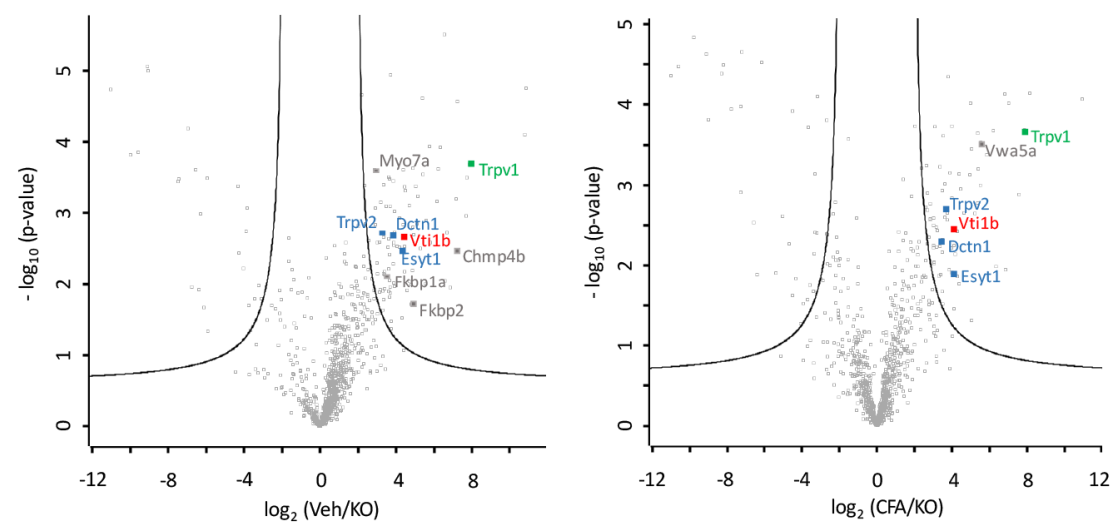

C

\section{Downregulated in CFA}

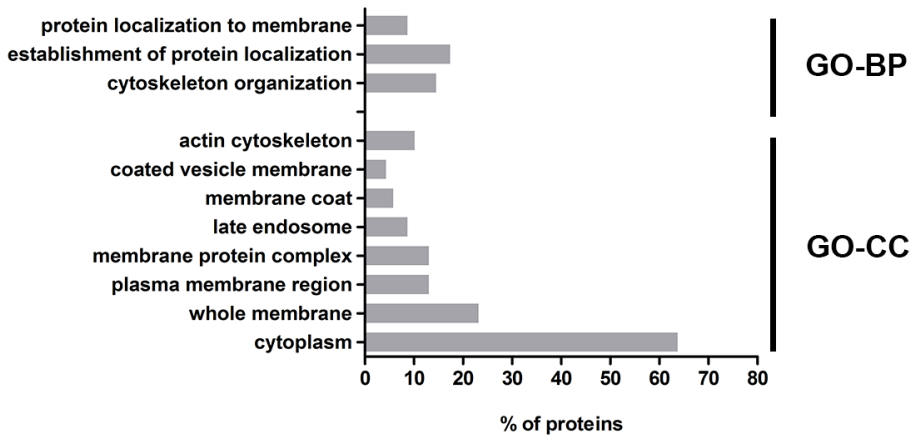

Upregulated in CFA

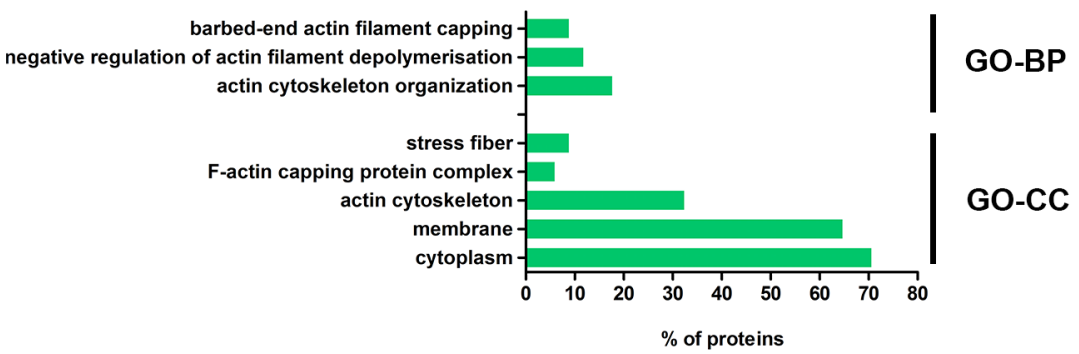


Figure 7

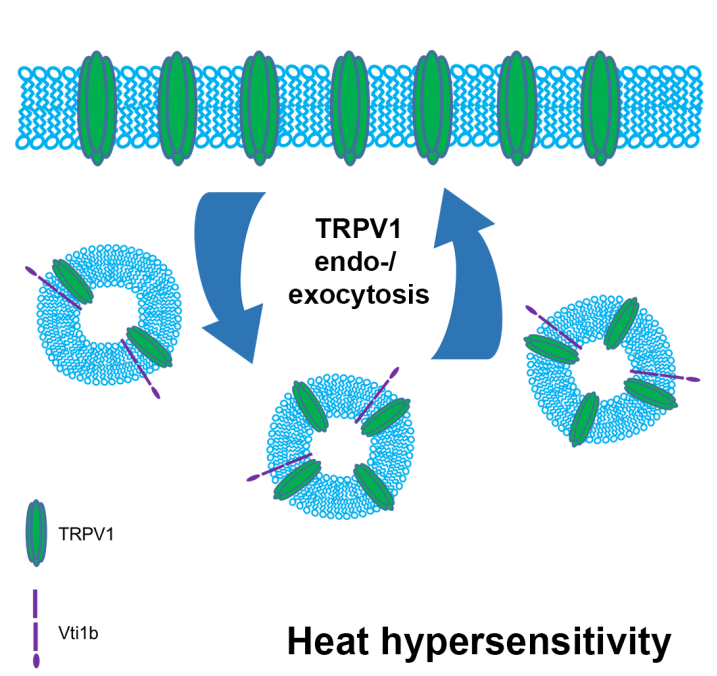

\section{Vti1b}

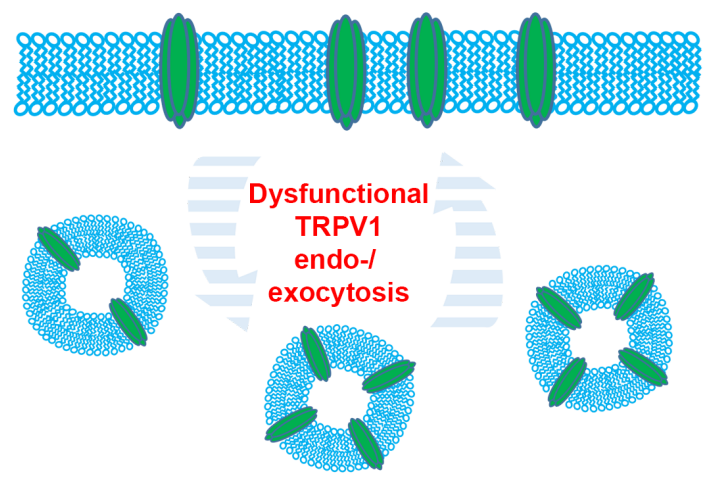

Heat hypersensitivity 


\section{List of Supplemental Digital Contents:}

Supplemental Digital Content 1: Table (.x/sx)

Table with details on all quantified proteins by mass spectrometry

Supplemental Digital Content 2: Figure (.pdf)

Correlation of all the MS sample replicates within and between groups

Supplemental Digital Content 3: Figure (.pdf)

Additional information about calcium imaging in IDRG neuronal cultures

Supplemental Digital Content 4: Figure (.pdf)

Additional data on in vivo Vti1b knockdown and behavioral testing

Supplemental Digital Content 5: Figure (.pdf)

TRPV1 N- and C-termini are both in close proximity to Vti1b in transfected HEK293 cells

Supplemental Digital Content 6: Figure (.pdf)

Whole Western blot of co-immunoprecipitation of TRPV1 and Vti1b in HEK293 cells

Supplemental Digital Content 7: Table (.x/sx)

List of significantly enriched members of the TRPV1 interactome:

Veh vs. KO and CFA vs. KO

Supplemental Digital Content 8: Table (.xlsx)

Differentially regulated members of the TRPV1 interactome: Summary (CFA vs. Veh), Gene Ontology analysis and comparison to pain-induced dynamics of the IDRG membrane proteome reported by Barry et al., 2018.

Supplemental Digital Content 9: Text (.pdf)

Legends for all Supplemental Digital Content Figures 


\section{Supplemental Digital Content 9:}

Figure legends for all Supplemental Digital Content Figures

Supplemental Digital Content 2: Correlation of all replicates within and between groups. Multi-scatter plot of $\log _{2}$-transformed abundance values of all 3 replicates of each group (KO, Veh and nCFA). The Pearson correlation coefficient was calculated for each comparison with Perseus (upper left corner of each scatter plot) to access the similarity of the replicates within and between the groups. On average, the samples showed high correlation (0.681-0.968). As expected, the correlation within one group was higher than between the groups of one replicate round.

\section{Supplemental Digital Content 3: Additional information about calcium imaging in IDRG neuronal cultures.}

(A) Quantification of effective siRNA-mediated knockdown of Vti1b in DRG neuronal cultures $72 \mathrm{~h}$ after transfection with control (CtIr) or Vti1b siRNA. The integrated intensity of Vti1bstaining is significantly reduced upon siRNA-mediated knockdown in 2 out of 3 independent cultures (replicate (rep) 1-3, in arbitrary units (AU)). CtIr siRNA vs. Vti1b siRNA: rep 1, ns; rep $2,{ }^{* * *} p<0.001$; rep 3, ${ }^{* * *} p<0.001 ; N>80$ neurons; $n=3$ independent cultures; two-way ANOVA followed by Bonferroni posttests.

(B) Stacked bar graphs display the fraction of responders (colored) and non-responders (white) to $1 \mu \mathrm{M}$ Caps given after 6 Caps pulses to estimate the extent of the TRPV1-positive population. CFA c vs. CFA si, ${ }^{* * *} p<0.0001$. Veh $c$ vs. CFA $c$, Veh $c,{ }^{*} p<0.0128$. Dynasore CFA $c$ vs. CFA $c,{ }^{* * *} p<0.0001$; count of responders in columns; $n=3-4$ independent cultures; Fisher's exact test.

(C) Response amplitudes (measured as peak of fluorescence ratio 340/380 above baseline) to $1 \mu \mathrm{M}$ Caps. Veh $\mathrm{c}$ vs. CFA $\mathrm{c}$. Veh $\mathrm{c},{ }^{* *} p=0.0057$; cell count in columns; $n=3-4$ cultures; one-way ANOVA followed by Holm-Sidak's multiple comparisons test.

Data represented as mean \pm SEM.

\section{Supplemental Digital Content 4: In vivo Vti1b knockdown followed by assessment of sensory behaviors.}

(A, left) Quantification of the basal sensitivity (measured as withdrawal latency) in the noninjected contralateral (con) paw to a radiant heat stimulus. (A, right) Normalization of withdrawal latencies of injected (ipsi) to contra paws (ipsi/con in \%) for each individual mouse. Mice were tested prior to virus injection (pre AAV) and three weeks after virus injection (pre CFA). All comparisons ns; $N>10$ mice for each group, $n=2$ independent cohorts; KruskalWallis test.

(B, left) Quantification of the basal sensitivity (measured as paw withdrawal latency) in the noninjected contralateral (con) paw to punctuate mechanical pressure. (B, right) Normalization of withdrawal latencies of injected (ipsi) to contra paws (ipsi/con in \%) for each individual mouse. Mice were tested prior to virus injection (pre AAV) and three weeks after virus injection (pre CFA). All comparisons ns; $N>10$ mice for each group, $n=2$ independent cohorts; KruskallWallis test.

(C, left) Mice were injected with Vti1 b miR or scramble miR followed by assessment of CFAinduced inflammatory pain three weeks later. Quantification of thermal hypersensitivity 
(measured as paw withdrawal latency) in the non-injected con paw to a radiant heat stimulus $24 \mathrm{~h}$ after CFA injection. (C, right) Normalization of withdrawal latencies of injected (ipsi) to con paws (ipsi/con in \%) for each individual mouse. * $p=0.0158 ; \mathrm{N}=11$ mice per group; $\mathrm{n}=$ 2 independent cohorts; Mann Whitney test.

(D, left) Mice were injected with Vti1b miR or scramble miR followed by assessment of CFAinduced inflammatory pain three weeks later. Quantitation of hypersensitivity (measured as withdrawal latency) in the non-injected con paw to punctuate mechanical pressure $24 \mathrm{~h}$ after CFA injection. ( $D$, right) Normalization of withdrawal latencies of injected (ipsi) to con paws (ipsi/con in \%) for each individual mouse. All comparisons, $n s, p=0.8371 ; N=8-10$ mice per group; $n=2$ independent cohorts; Mann Whitney test.

(E, left) Mice were injected with Vti1b miR or scramble miR followed by assessment of CFAinduced inflammatory pain three weeks later. Quantitation of hypersensitivity (measured as withdrawal latency) of the injected (ipsi) paw to punctuate mechanical pressure $48 \mathrm{~h}$ after CFA injection (same cohort that had been tested for thermal hypersensitivity $24 \mathrm{~h}$ after CFA, Fig. 4F). (E, middle) Quantitation of hypersensitivity (measured as withdrawal latency) of the noninjected paw to punctuate mechanical pressure $48 \mathrm{~h}$ after CFA injection. (E, right) Normalization of withdrawal latencies of injected (ipsi) to con paws (ipsi/con in \%) for each individual mouse. All comparisons, $n s, p=0.7396 ; \mathrm{N}=7-10$ mice per group; $\mathrm{n}=2$ independent cohorts; Mann Whitney test.

Data represented as mean \pm SEM. All comparisons are ns if not indicated otherwise.

\section{Supplemental Digital Content 5: TRPV1 N- and C-termini are both in close proximity to Vti1b in transfected HEK293 cells.}

PLA with antibodies (Ab) targeted against Vti1b-myc-DDK (either myc or Vti1b) and different parts of TRPV1 (N-terminus, N-term; C-terminus, C-term) on HEK293 cells transiently transfected with indicated TRPV1 deletion constructs (left, scheme of deletion constructs, AA: amino acids, S1-S6: transmembrane domains). Co-transfection of Vti1b-myc-DDK with either the N-term-transmembrane (TMD) or the TMD-C-term construct of TRPV1 yielded prominent PLA signal, which was largely comparable to full-length TRPV1-YFP + Vti1b-myc-DDK. The significant difference in PLA signal between TMD-C term and full length TRPV1 is likely due to expression differences. PLA on cells only transfected with the full length TRPV1-YFP construct (without Vti1b-myc-DDK) served as negative control and yielded hardly any PLA signal, as expected. Comparison as indicated, ${ }^{* * *} p<0.001 ; \quad N=26-108$ cells; $n=2-3$ independent cultures; Kruskal-Wallis test followed by Dunn's multiple comparison tests. Data represented as mean \pm SEM.

\section{Supplemental Digital Content 6: Whole Western blot of co-immunoprecipitation of TRPV1 and Vti1b in HEK293 cells.}

Vti1b co-immunoprecipitates with TRPV1 (V1) in HEK293 cells (compare Fig. 5C). 'Input' represents the protein lysate prior to the addition of an antibody. ' $N$ ' $=\alpha-T R P V 1$ coimmunoprecipitation with an antibody targeting an N-terminal region of TRPV1; ' $\mathrm{C}$ ' = $\alpha$-TRPV1 co-immunoprecipitation with an antibody targeting a C-terminal region of TRPV1. Mock, cells transfected with empty $\mathrm{pCMV-Sport6}$ plasmid. 


\section{Supplemental Digital Content 2}

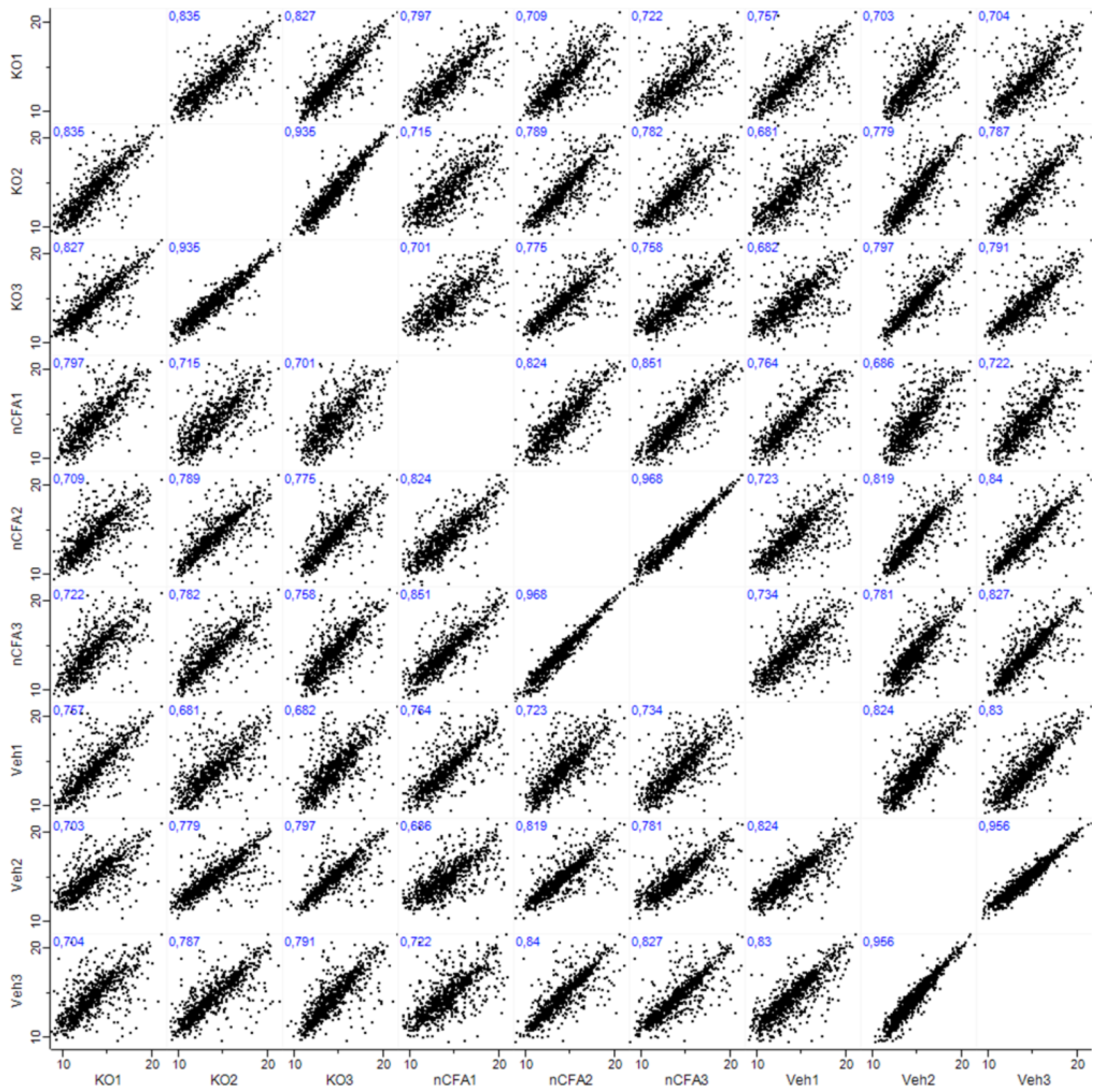


Supplemental Digital Content 3

A

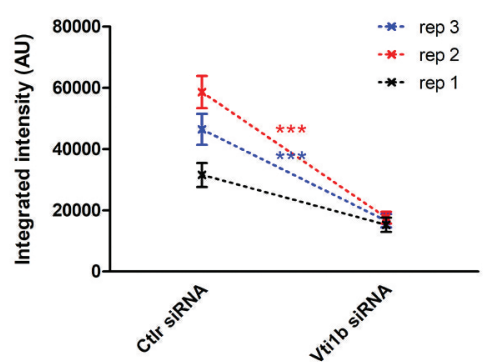

B

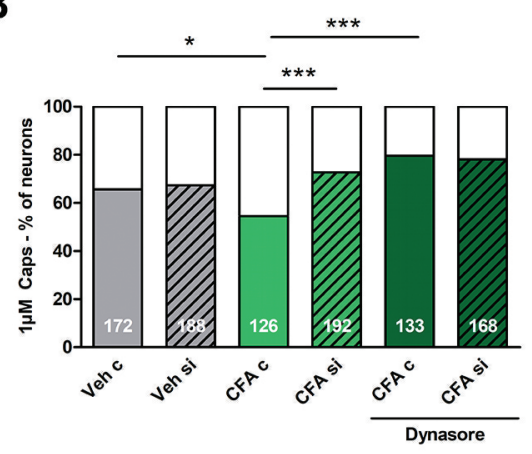

C

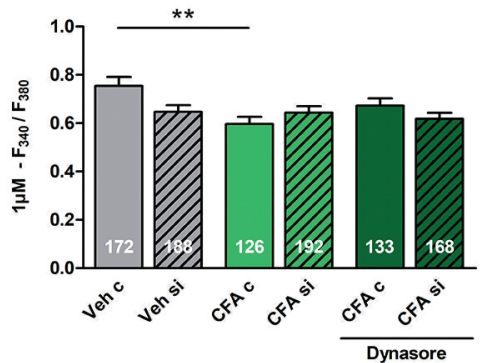




\section{Supplemental Digital Content 4}

A

Pretests - Thermal sensitivity
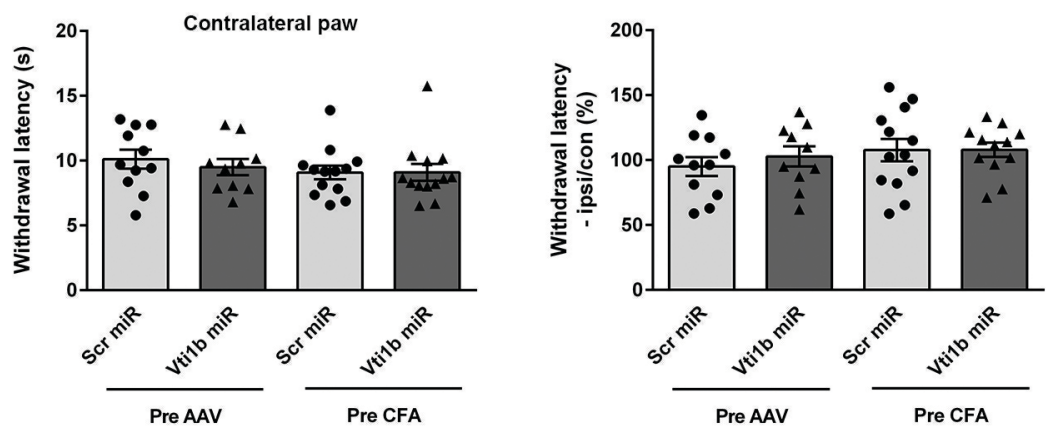

B

Pretests - Mechanical sensitivity

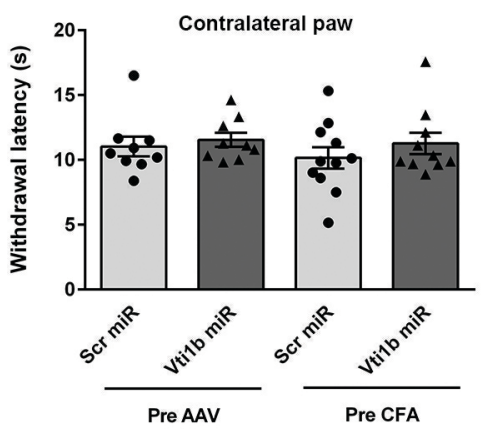

C CFA 24h - Thermal sensitivity
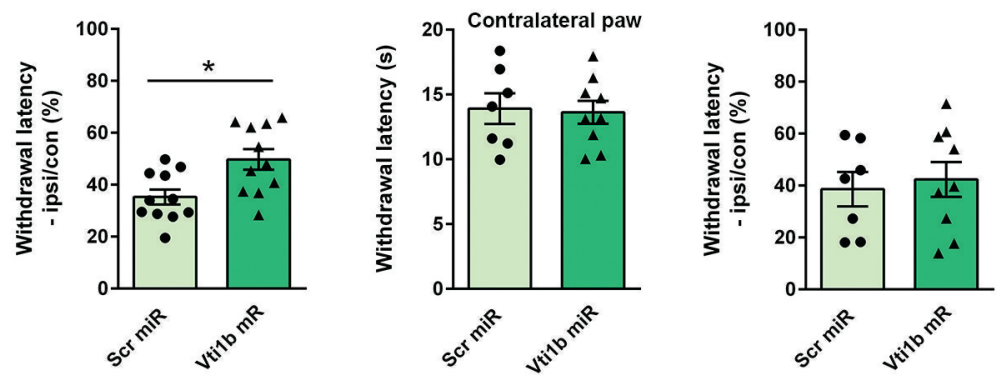

E

CFA 48h - Mechanical sensitivity
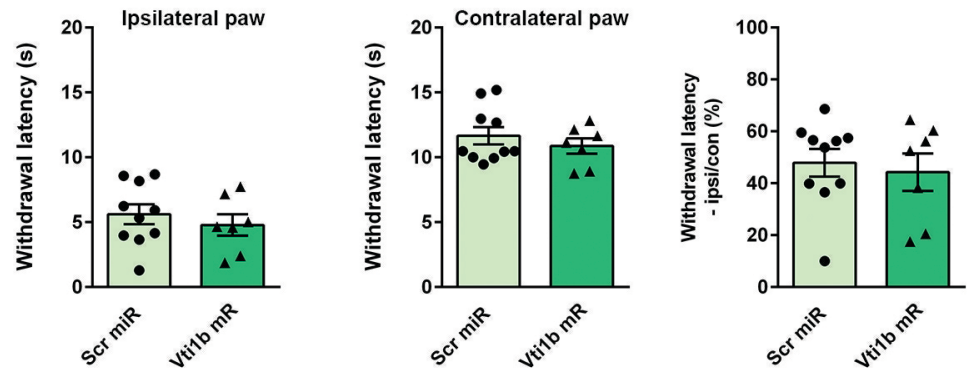


\section{Supplemental Digital Content 5}

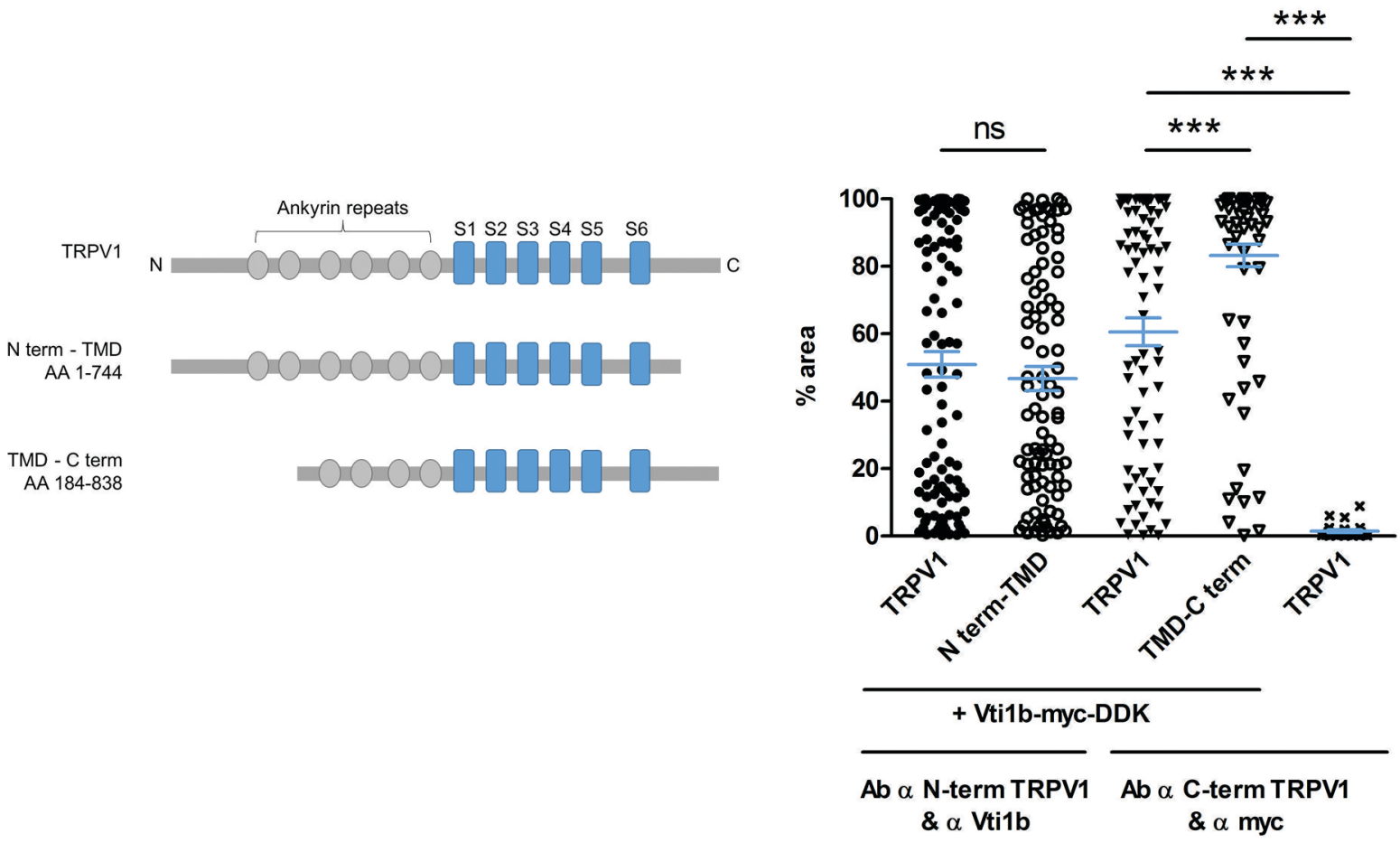




\section{Supplemental Digital Content 6}

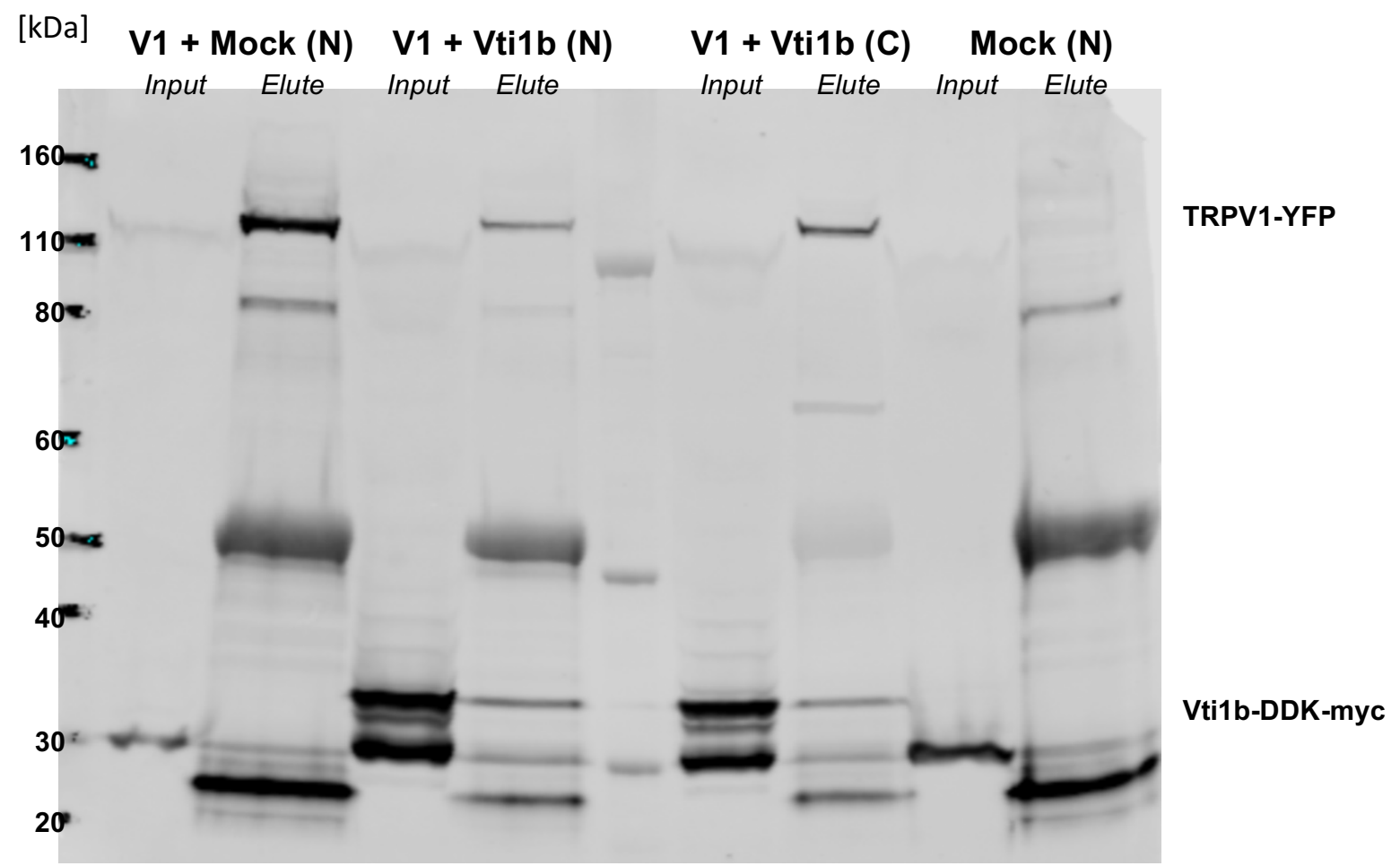

